\title{
CRISPR/Cas9 Directed Mutagenesis of OsGA20ox2 in High Yielding Basmati Rice (Oryza sativa L.) Line and Comparative Proteome Profiling of Unveiled Changes Triggered by Mutations
}

\author{
Gul Nawaz ${ }^{1}\left(\mathbb{D}\right.$, Babar Usman $^{1}\left(\mathbb{D}\right.$, Neng Zhao ${ }^{1}$, Yue Han ${ }^{1}$, Zhihua Li ${ }^{1}$, Xin Wang ${ }^{1}$, \\ Yaoguang $\mathrm{Liu}^{2, *}$ and Rongbai $\mathrm{Li}^{1, *}$ \\ 1 College of Agriculture, State Key Laboratory for Conservation and Utilization of Subtropical \\ Agro-Bioresources, Guangxi University, Nanning 530004, China; gulnawazmalik@yahoo.com (G.N.); \\ babarusman119@gmail.com (B.U.); nengzhao_gxu@163.com (N.Z.); hanyue0624@126.com (Y.H.); \\ lizhihua-88@163.com (Z.L.); xinwang0112@126.com (X.W.) \\ 2 State Key Laboratory for Conservation and Utilization of Subtropical Agricultural Bioresources, \\ South China Agricultural University, Guangzhou 510642, China \\ * Correspondence: ygliu@scau.edu.cn (Y.L.); lirongbai@126.com (R.L.); \\ Tel.: +86-20-8528-1908 (Y.L.); +86-136-0009-4135 (R.L.)
}

Received: 16 July 2020; Accepted: 23 August 2020; Published: 26 August 2020

\begin{abstract}
In rice, semi-dwarfism is among the most required characteristics, as it facilitates better yields and offers lodging resistance. Here, semi-dwarf rice lines lacking any residual transgene-DNA and off-target effects were generated through CRISPR/Cas9-guided mutagenesis of the OsGA20ox2 gene in a high yielding Basmati rice line, and the isobaric tags for relative and absolute quantification (iTRAQ) strategy was utilized to elucidate the proteomic changes in mutants. The results indicated the reduced gibberellins $\left(\mathrm{GA}_{1}\right.$ and $\left.\mathrm{GA}_{4}\right)$ levels, plant height $(28.72 \%)$, and flag leaf length, while all the other traits remained unchanged. The OsGA20ox2 expression was highly suppressed, and the mutants exhibited decreased cell length, width, and restored their plant height by exogenous $\mathrm{GA}_{3}$ treatment. Comparative proteomics of the wild-type and homozygous mutant line (GXU43_9) showed an altered level of 588 proteins, 273 upregulated and 315 downregulated, respectively. The identified differentially expressed proteins (DEPs) were mainly enriched in the carbon metabolism and fixation, glycolysis/gluconeogenesis, photosynthesis, and oxidative phosphorylation pathways. The proteins (Q6AWY7, Q6AWY2, Q9FRG8, Q6EPP9, Q6AWX8) associated with growth-regulating factors (GRF2, GRF7, GRF9, GRF10, and GRF11) and GA (Q8RZ73, Q9AS97, Q69VG1, Q8LNJ6, Q0JH50, and Q5MQ85) were downregulated, while the abscisic stress-ripening protein 5 (ASR5) and abscisic acid receptor (PYL5) were upregulated in mutant lines. We integrated CRISPR/Cas9 with proteomic screening as the most reliable strategy for rapid assessment of the CRISPR experiments outcomes.
\end{abstract}

Keywords: rice; gibberellins; plant height; CRISPR/Cas9; OsGA20ox2; proteomic analysis

\section{Introduction}

Rice is a very important crop for the developing world and is considered a staple food for half of the world's population [1-4]. Basmati rice has a unique specialty with good palatability, longer shelf life, easy digestibility, and good aroma [5]. The tall stature of traditional Basmati varieties is a big drawback as such varieties are easily lodged, which negatively affects the rice yield [6]. Plant height $(\mathrm{PH})$ is an important character owing to critical roles in the plant architecture and adaptability to the environmental conditions that are directly linked with yield $[7,8]$. The number and length of the 
internodes determine the $\mathrm{PH}[9]$, which results in improved lodging resistance capacity and better biomass production due to the short stature [10]. Gibberellin (GA) is a plant growth hormone and many genes are vital for GA biosynthesis and signaling, which plays decisive roles in the metabolism of brassinosteroid and influences the stem length regulation in plants [11]. Mutations in components participating in GA signaling and metabolism pathways exhibit notable dwarf or semi-dwarf plant phenotype [12]. The tall phenotype is controlled by the $S D 1$ (semi dwarf1) allele while its recessive allele (sd1) controls the semi-dwarf phenotype $[13,14]$. The OsGA20ox2 has 3 exons and 2 introns, a total of 389 amino acids are encoded by this gene and GA20 oxidase2 is a major enzyme for GA synthesis [13]. Mostly, GAs, consist of large groups of diterpenoid carboxylic acids such as GA1 and GA4, and display a vital role in the development and growth of plants [15,16]. OsGA20ox2 is mainly expressed in the stem, and mutations in OsGA200x2 resulted in the production of a moderate amount of GA, and its mutants with loss-of-function exhibit a semi-dwarf phenotype $[10,17,18]$. The miracle rice cultivar IR8 has a short plant height because of the SD1 gene mutation and enabled extraordinary yield increases and facilitated the prevention of food shortages $[13,18,19]$. The OsGA20ox2 mutants have no negative effects on the morphological and yield-related traits and extensive efforts have been made by the research community for achieving the semi-dwarf phenotype in rice through molecular breeding and $\mathrm{PH}$ can be restored in mutants similar to that of WT (wild type) plants by exogenous $\mathrm{GA}_{3}$ treatment [20-22].

The targeted and effective gene mutations have been successfully achieved by the CRISPR/Cas9 (clustered regularly interspaced short palindromic repeats/CRISPR-associated protein 9) system in rice for improving the existing varieties and to develop new mutant lines by targeting one or multiple genes [23-25]. CRISPR/Cas9 is a tremendous technique for precise and targeted editing of the genome of plants and animals. ZFNs (zinc finger nucleases) and TALEN (transcriptional activator-like effector nuclease) genome editing techniques were established before the CRISPR/Cas9, but because of the simplicity and flexibility, rapidness, multiplexing capacity, high efficiency, and mutation frequency, this system gained worldwide popularity and is widely accepted by researchers [26,27]. The CRISPR/Cas9 technique has been successfully applied in Arabidopsis [28,29], rice [28,30-32], maize [33], wheat [31,34], sorghum [28], soybean [35-37], and tomato [38], and the resulted mutations are transmitted to the next generations according to the classical inheritance principles [39].

The development of the proteomics over the last few decades has greatly contributed in omics and is now accepted widely to study various species [40-44]. To comprehend the effects of mutations on the genome of plants, whole genome-wide profiling of proteins or transcripts is an efficient way to investigate the distinct variations in diverse biological and molecular processes [45]. The dramatic improvement in the methods used in molecular biology, extensive profiling of transcripts, and iTRAQ (isobaric tags for relative and absolute quantification)-based proteomic analysis can provide insights into a universal view of genes and protein expression patterns and can be helpful to understand the potential molecular mechanism behind the mutagenesis [46,47]. The iTRAQ has been applied successfully in plant species to recognize the diverse biological processes, including Arabidopsis [48], rice [49,50], wheat [51], and maize [52]. It is an effective and high-throughput approach with high sensitivity and accuracy, multiplexing capacity, and repeatability. However, this tremendous method has not yet been utilized to investigate which mechanisms are underlying the semi-dwarf phenotype. In our study, we have exploited the CRISPR/Cas9 technology to knock out the OsGA20ox2 gene in Basmati rice, and earmark and delicate mutations in the OsGA20ox2 gene and homozygous $\mathrm{T}_{1}$ semi-dwarf mutant lines were achieved effectively, with significantly reduced PH and GA content without disturbing other agronomic characters. To further understand the functional roles of the OsGA20ox2 gene, comparative iTRAQ analysis was performed to elucidate the effects of mutations on the protein level. Our results provide new hints in understanding OsGA20ox2 functions and suggest that the proteomic screening is a reliable tool for assessment of CRISPR experiments. By this tactic, our aim was to infer the mechanisms that are more closely associated with rice dwarfism. 


\section{Results}

\subsection{Editing of OsGA20ox2 Gene and Identification of Transgene-Free Plants}

We used 165 calli for the $A$. tumefaciens transformation and a total of 30 rice seedlings were achieved. Mutant lines were screened by using hygromycin phosphotransferase (HPT-F/R) primers, and the final product was amplified and confirmed in mutants (Supplementary file 1, Table S1, Figure S1A). A high rate of mutation was observed in both targets of the OsGA20ox2 gene, with a total mutation efficiency of $70 \%\left(73.33 \%\right.$ for $\mathrm{T}_{1}$ and $66.33 \%$ for $\left.\mathrm{T}_{2}\right)$. Among 30 plants, there were $8(26.67 \%)$ homozygous, $9(30 \%)$ biallelic (heterozygous), $4(13.33 \%)$ heterozygous (mono-allelic), and 1 (3.33\%) chimeric. A total of 30 mutant lines were obtained for $\mathrm{T}_{2}$, including $7(23.33 \%)$ homozygous, 10 (33.33\%) biallelic (heterozygous), 1 (3.33\%) heterozygous (mono-allelic), and 2 (6.67\%) were chimeric (Figure 1A,B). Mutated alleles were amplified from the genomic DNA of $\mathrm{T}_{0}$ mutant lines and the sequencing chromatograms with overlapping traces were decoded (Figure 1C).

We selected four transgene-DNA-free (T-DNA-free) homozygous lines (GXU43_2, GXU43_4, GXU43_9, and GXU43_19) for agronomic traits evaluation. GXU43_2 showed homozygous mutations with $1 \mathrm{bp}$ insertion and $3 \mathrm{bp}$ deletion, the mutant GXU43_4 showed $27 \mathrm{bp}$ and 1 bp deletions, the homozygous mutant GXU43_9 revealed 172 bp and 12 bp deletions, and finally, the homozygous mutant line GXU43_19 resulted in 4 bp deletion and 1 bp insertion on the first and second target sites, respectively. The sequencing analysis of these homozygous mutants showed that the mutations were stable and inheritable in $T_{1}, T_{2}$, and subsequent $T_{3}$ generations (Figure 1D). The plant numbers and the corresponding mutations in both target sites are mentioned in Supplementary file 1, Table S2. The thirty plants were selected, and the DNA was amplified for 5 loci of each target site with the highly ranked off-target potential, and no secondary off-target mutations were detected in sequencing results (Supplementary file 1, Table S3).

A

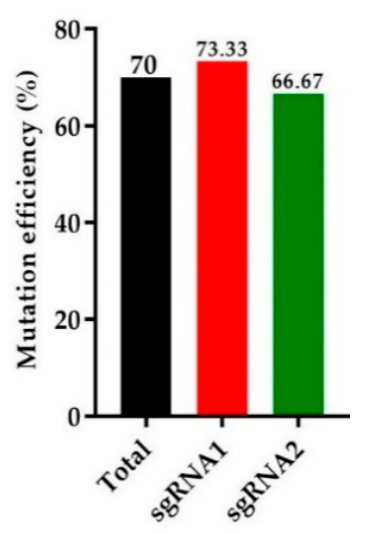

B

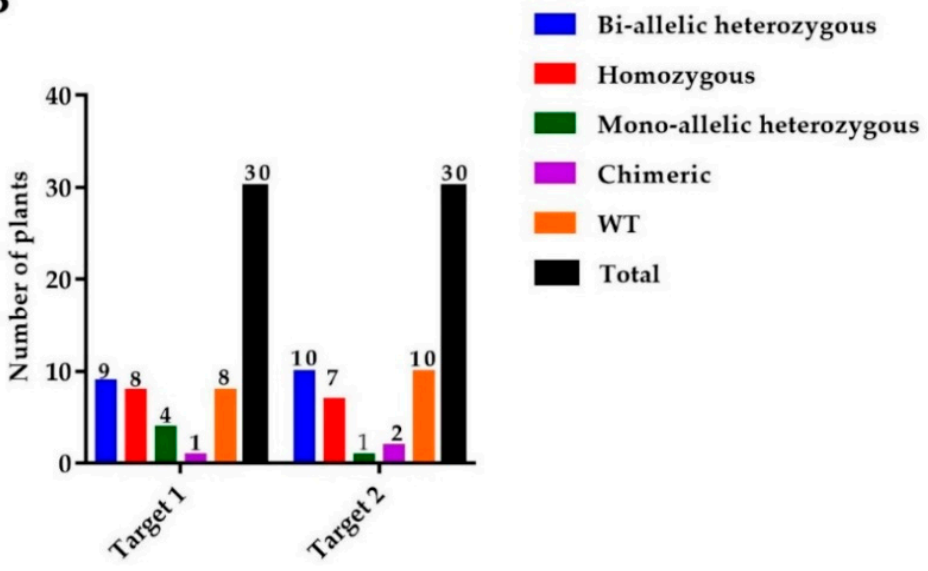

Figure 1. Cont. 
C

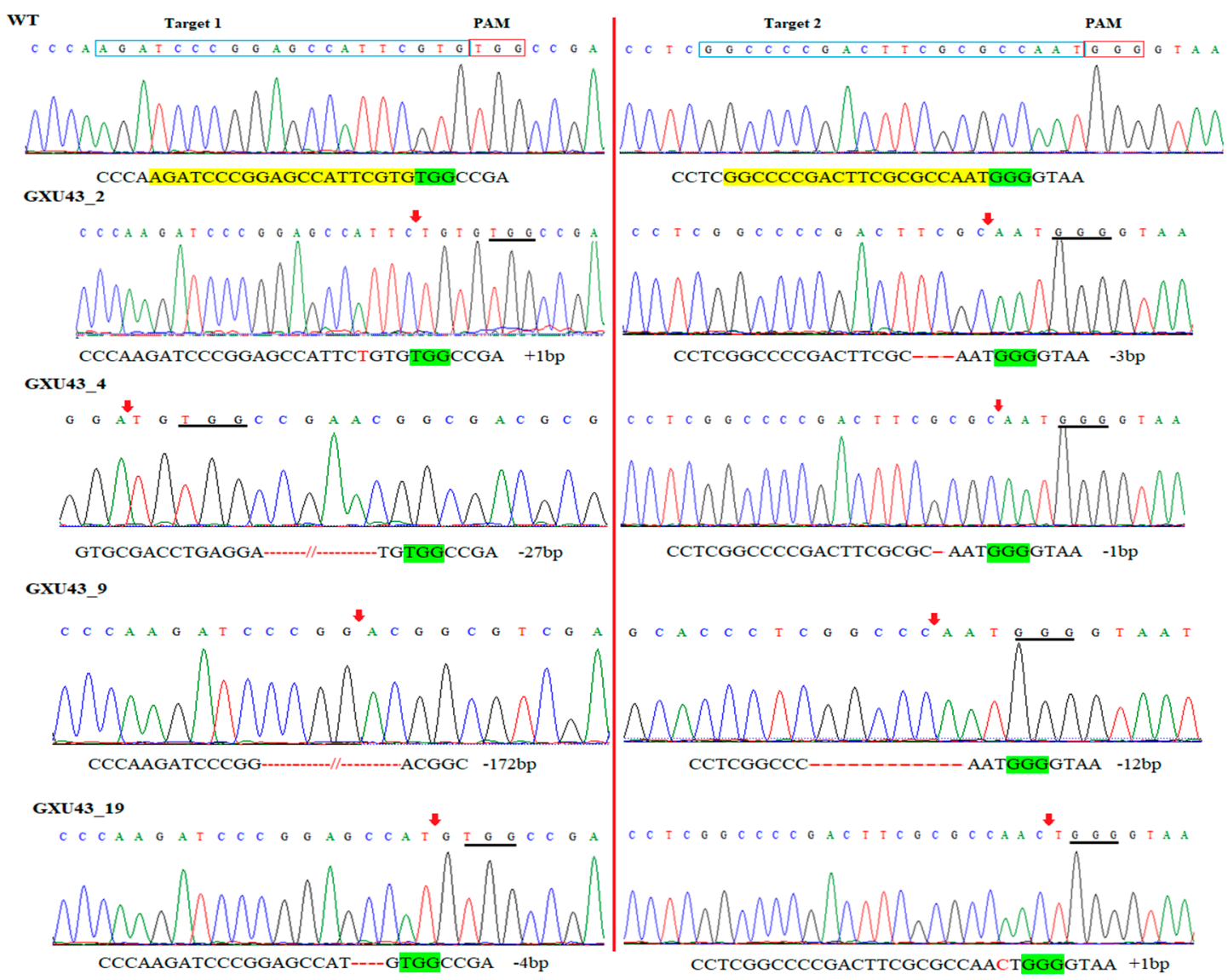

D

\begin{tabular}{|c|c|c|c|}
\hline Generation & Genotypes & Target 1 & Mutations \\
\hline & WT & CCCAAGATCCCGGAGCCATTCGTGTGGCCGA & \\
\hline $\mathrm{T} 1$ & GXU43_2 & CCCAAGATCCCGGAGCCATTCTGTGTGGCCGA & $+1 \mathrm{bp}$ \\
\hline $\mathrm{T} 2$ & GXU43_2 & CCCAAGATCCCGGAGCCATTCTGTGTGGCCGA & $+1 \mathrm{bp}$ \\
\hline T3 & GXU43_2 & CCCAAGATCCCGGAGCCATTCTGTGTGGCCGA & $+1 \mathrm{bp}$ \\
\hline $\mathrm{T} 1$ & GXU43_4 & GTGCGACCTGAGGA------//--------TGTGGCCGA & $-27 \mathrm{bp}$ \\
\hline $\mathrm{T} 2$ & GXU43_4 & GTGCGACCTGAGGA------///--------TGTGGCCGA & $-27 \mathrm{bp}$ \\
\hline $\mathrm{T} 3$ & GXU43_4 & GTGCGACCTGAGGA-----//------TGTGGCCGA & $-27 \mathrm{bp}$ \\
\hline T1 & GXU43_9 & CCCAAGATCCCGG---- & $-172 b \mathrm{p}$ \\
\hline $\mathrm{T} 2$ & GXU43_9 & CCCAAGATCCCGG-- & $-172 b p$ \\
\hline $\mathrm{T} 3$ & GXU43_9 & 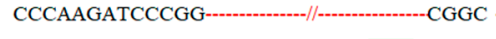 & $-172 \mathrm{bp}$ \\
\hline $\mathrm{T} 1$ & GXU43_19 & CCCAAGATCCCGGAGCCAT---- GTGGCCGA & $-4 \mathrm{bp}$ \\
\hline $\mathrm{T} 2$ & GXU43_19 & CCCAAGATCCCGGAGCCAT---- GTGGCCGA & $-4 \mathrm{bp}$ \\
\hline T3 & GXU43_19 & CCCAAGATCCCGGAGCCAT - & $-4 \mathrm{bp}$ \\
\hline
\end{tabular}

$\begin{array}{lcc}\text { Target 2 } & \text { PAM } & \text { Mutations } \\ \text { CCTCGGCCCCGACTTCGCGCCAATGGGGTAA } & \\ \text { CCTCGGCCCCGACTTCGC---AATGGGGTAA } & -3 \mathrm{bp} \\ \text { CCTCGGCCCCGACTTCGC---AATGGGGTAA } & -3 \mathrm{bp} \\ \text { CCTCGGCCCCGACTTCGC---AATGGGGTAA } & -3 \mathrm{bp} \\ \text { CCTCGGCCCCGACTTCGCGC-AATGGGGTAA } & -1 \mathrm{bp} \\ \text { CCTCGGCCCCGACTTCGCGC-AATGGGGTAA } & -1 \mathrm{bp} \\ \text { CCTCGGCCCCGACTTCGCGC-AATGGGGTAA } & -1 \mathrm{bp} \\ \text { CCTCGGCCC---- AATGGGGTAA } & -12 \mathrm{bp} \\ \text { CCTCGGCCC------AATGGGTAA } & -12 \mathrm{bp} \\ \text { CCTCGGCCC--- } & \\ \text { CCTCGGCCCCGACTTCGCGCCAACTGGGGTAA } & +1 \mathrm{bp} \\ \text { CCTCGGCCCCACTTCGCGCCAACTGGGGTAA } & +1 \mathrm{bp} \\ \text { CCTCGGCCCCGACTTCGCGCCAACTGGGGTAA } & +1 \mathrm{bp}\end{array}$

Figure 1. Identification of mutations generated by the clustered regularly interspaced short palindromic repeats/CRISPR-associated protein 9 (CRISPR/Cas9) system. (A) The mutation efficiency of sgRNAs (single guided RNAs), (B) The mutation rate in $\mathrm{T}_{0}$ (Transgenic) generation, (C) sequencing chromatograms of WT (wild type) and homozygous mutant lines for Target 1 and Target 2, and (D) the alignment of sequences for $T_{1}, T_{2}$, and $T_{3}$ generations, respectively. The target sequence is painted in yellow, while the PAM (protospacer adjacent motif) is in the green background, and insertions/deletions are represented by red hyphens and letters. The analysis was carried out in three replications for each line. 


\subsection{T-DNA-Free Mutants and Segregation Ratio in the $T_{1}$ Generation}

Homozygous mutants of $\mathrm{T}_{0}$ and $\mathrm{T}_{1}$ were grown and 50 plants were evaluated to analyze the transformation patterns and thus to detect the exogenous DNA in the mutant lines. The plants were believed to be T-DNA-free if they failed to amplify against HPT and Cas9-specific primers (Supplementary file 1, Table S1). The results showed that 30 plants were amplified to the Cas 9 vector sequence and 20 lines showed no amplification, and therefore, were considered as T-DNA-free. The frequency of such plants was recorded at 40\% (Supplementary File 1, Figure S1B). The heterozygous (mono and biallelic) $\mathrm{T}_{1}$ plants of GXU43_8 were segregated according to Mendelian inheritance (1:2:1). All the $T_{1}$ plants obtained from $T_{0}$ homozygous plants (GXU43_2, GXU43_4,GXU43_9, and GXU43_19) also showed homozygosity for the same mutations, which indicated the stable transmission of mutations to the subsequent generations (Supplementary File 1, Table S4).

\subsection{Endogenous GA Content and $\mathrm{PH}$ in $\mathrm{T}_{1}, \mathrm{~T}_{2}$, and $\mathrm{T}_{3}$ Generations}

The mutant lines exhibited decreased $\mathrm{PH}$ (plant height) and GA content $\left(\mathrm{GA}_{1}, \mathrm{GA}_{4}\right)$ as compared with WT plants. The mutant line GXU43_9 showed a minimum PH of 114.77, 115.55, and $113.98 \mathrm{~cm}$ in $\mathrm{T}_{1}, \mathrm{~T}_{2}$, and $\mathrm{T}_{3}$ generations respectively, and the $\mathrm{GA}_{1}$ and $\mathrm{GA}_{4}$ content $\left(0.95\right.$ and 0.84 in $\mathrm{T}_{1}, 0.91$ and 0.81 in $\mathrm{T}_{2}$, and 0.88 and $0.87 \mu \mathrm{g} / \mathrm{kg}$ fresh weight (FW) in $\mathrm{T}_{3}$ generation, respectively), while WT showed maximum plant height $(161.31 \mathrm{~cm})$ and gibberellins $(1.66$ and $1.54 \mu \mathrm{g} / \mathrm{kg} \mathrm{FW})$ content. The results revealed a significant and positive correlation among endogenous GA content and PH of WT and transgenic plants (Table 1$)$.

Table 1. Plant height (PH) and gibberellin (GA) content ( $\mu \mathrm{g} / \mathrm{kg} \mathrm{FW})$ in $\mathrm{T}_{1}, \mathrm{~T}_{2}$, and $\mathrm{T}_{3}$ mutant lines.

\begin{tabular}{ccccc}
\hline Gen & Lines & GA $_{1}$ & GA $_{\mathbf{4}}$ & PH \\
\hline \multirow{4}{*}{$\mathrm{T}_{1}$} & WT & $1.66 \pm 0.14$ & $1.54 \pm 0.16$ & $161.31 \pm 3.9$ \\
& GXU43_2 & $1.19 \pm 0.09^{* *}$ & $1.12 \pm 0.12^{* *}$ & $128.25 \pm 4.2^{* *}$ \\
& GXU43_4 & $1.10 \pm 0.10^{* *}$ & $1.05 \pm 0.11^{* *}$ & $118.25 \pm 2.9^{* *}$ \\
& GXU43_9 & $0.95 \pm 0.08^{* *}$ & $0.84 \pm 0.10^{* *}$ & $114.77 \pm 3.1^{* *}$ \\
& GXU43_19 & $1.20 \pm 0.12^{* *}$ & $1.24 \pm 0.17^{* *}$ & $122.24 \pm 3.1^{* *}$ \\
\hline \multirow{4}{*}{$\mathrm{T}_{2}$} & WT & $1.59 \pm 0.18$ & $1.65 \pm 0.15$ & $164.45 \pm 3.7$ \\
& GXU43_2 & $1.21 \pm 0.11^{* *}$ & $1.24 \pm 0.10^{* *}$ & $125.90 \pm 4.3^{* *}$ \\
& GXU43_4 & $1.20 \pm 0.09^{* *}$ & $1.15 \pm 0.12^{* *}$ & $117.53 \pm 2.8^{* *}$ \\
& GXU43_9 & $0.91 \pm 0.11^{* *}$ & $0.81 \pm 0.12^{* *}$ & $115.55 \pm 3.5^{* *}$ \\
& GXU43_19 & $1.14 \pm 0.13^{* *}$ & $1.30 \pm 0.13^{* *}$ & $123.35 \pm 3.3^{* *}$ \\
\hline \multirow{4}{*}{$\mathrm{T}_{3}$} & WT & $1.60 \pm 0.15$ & $1.63 \pm 0.17$ & $163.31 \pm 3.9$ \\
& GXU43_2 & $1.14 \pm 0.10^{* *}$ & $1.29 \pm 0.11^{* *}$ & $126.25 \pm 4.2^{* *}$ \\
& GXU43_4 & $1.20 \pm 0.12^{* *}$ & $1.35 \pm 0.13^{* *}$ & $116.25 \pm 2.9^{* *}$ \\
& GXU43_9 & $0.88 \pm 0.13^{* *}$ & $0.87 \pm 0.12^{* *}$ & $113.98 \pm 3.1 * *$ \\
& GXU43_19 & $1.21 \pm 0.15^{* *}$ & $1.22 \pm 0.14^{* *}$ & $121.24 \pm 3.1 * *$ \\
\hline
\end{tabular}

Gen: generations, FW: fresh weight, PH: plant height, GA: gibberellins. Mean data for three independent replicates. ** represent a significant difference at $p \leq 0.01$.

\subsection{Performance of Agronomic and Quality Traits}

The data for the major agronomic traits of mutant and WT plants were recorded at 120 days after growing. The mean results for morphological traits expressed a significant difference amongst WT and mutant plants in PH (Figure 2A) and FLL (flag leaf length), while semi-dwarf lines showed slightly shorter PL (panicle length), with no difference in PN (panicle numbers), FLW (flag leaf width), GNPP (grain number per panicle), SSR (seed setting rate), and GW(1000-grain weight), YPP (yield per plant), GL (grain length), and GWD (grain width). We selected the four homozygous mutant lines GXU43_2, GXU43_4, GXU43_9, and GXU43_19, and the results of data for three consecutive generations revealed that the PH and FLL of mutants were significantly decreased (Table 2). However, 
grain appearance and shape were not altered (Figure 2B). Mutant lines showed shortened internodal length than WT plants (Figure 2C).

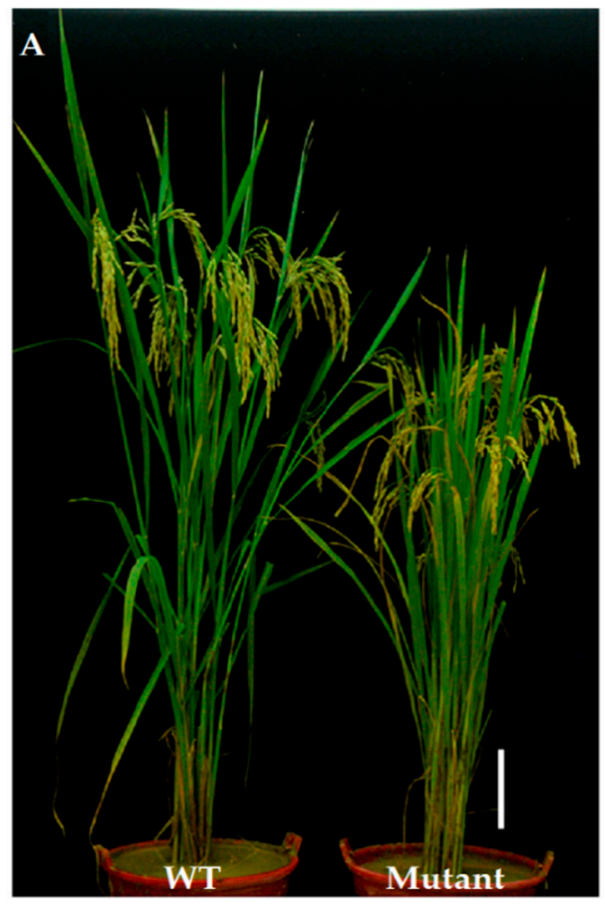

B

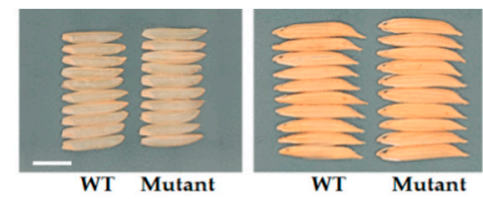

C

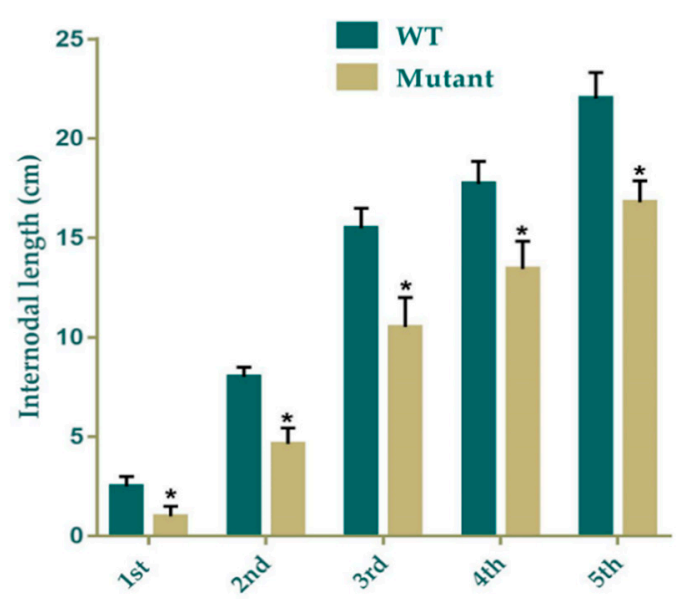

Figure 2. Phenotypic appearance of OsGA20ox2 in GXU43_9 and WT. (A) Plant height of mutant lines and WT after the heading stage. Bar $=15 \mathrm{~cm}$. (B) Grain phenotype of mutant line and WT; Bar $=5 \mathrm{~mm}$. (C) The lengths of internodes in mutant line and WT. The "*" denotes the significant difference at $p<0.01$. Values are means \pm standard deviation (SD) ( $n=10$ plants). 
Table 2. Performance of major agronomic traits in WT and mutant lines.

\begin{tabular}{|c|c|c|c|c|c|c|c|c|c|c|c|}
\hline Gen & Line & PN & PL (cm) & FLL (cm) & FLW (cm) & GNPP & SSR (\%) & GW (g) & YPP (g) & GL mm & GWD mm \\
\hline \multirow{5}{*}{$\mathrm{T}_{1}$} & WT & $9.91 \pm 0.8$ & $27.16 \pm 1.4$ & $49.97 \pm 3.39$ & $1.75 \pm 0.1$ & $145 \pm 12$ & $87.12 \pm 5.9$ & $29.34 \pm 1.3$ & $31.53 \pm 2.1$ & $8.52 \pm 0.4$ & $2.41 \pm 0.2$ \\
\hline & GXU43_2 & $9.17 \pm 0.3^{\mathrm{ns}}$ & $26.41 \pm 1.3^{\mathrm{ns}}$ & $38.63 \pm 2.40^{* *}$ & $1.61 \pm 0.2^{\mathrm{ns}}$ & $148 \pm 10^{\mathrm{ns}}$ & $92.10 \pm 4.1^{\mathrm{ns}}$ & $29.63 \pm 1.8^{\mathrm{ns}}$ & $31.85 \pm 1.3^{\mathrm{ns}}$ & $8.19 \pm 0.3^{\mathrm{ns}}$ & $2.49 \pm 0.3^{\mathrm{ns}}$ \\
\hline & GXU43_4 & $10.28 \pm 0.5^{\mathrm{ns}}$ & $26.15 \pm 2.5^{\mathrm{ns}}$ & $39.13 \pm 2.13 * *$ & $1.71 \pm 0.3^{\text {ns }}$ & $147 \pm 11^{\mathrm{ns}}$ & $91.33 \pm 5.1^{\mathrm{ns}}$ & $30.27 \pm 1.1^{\mathrm{ns}}$ & $30.41 \pm 1.2^{\mathrm{ns}}$ & $8.61 \pm 0.4^{\mathrm{ns}}$ & $2.35 \pm 0.4^{\mathrm{ns}}$ \\
\hline & GXU43_9 & $10.29 \pm 0.6^{\mathrm{ns}}$ & $24.98 \pm 1.9^{\mathrm{ns}}$ & $37.43 \pm 2.15^{* *}$ & $1.64 \pm 0.1^{\mathrm{ns}}$ & $149 \pm 09^{\mathrm{ns}}$ & $90.44 \pm 5.3^{\mathrm{ns}}$ & $30.29 \pm 2.2^{\mathrm{ns}}$ & $32.53 \pm 1.4^{\mathrm{ns}}$ & $9.10 \pm 0.4^{\mathrm{ns}}$ & $2.40 \pm 0.4^{\mathrm{ns}}$ \\
\hline & GXU43_19 & $10.75 \pm 0.4^{\mathrm{ns}}$ & $25.30 \pm 1.3^{\mathrm{ns}}$ & $40.33 \pm 1.85^{* *}$ & $1.55 \pm 0.3^{\mathrm{ns}}$ & $146 \pm 12^{\mathrm{ns}}$ & $93.03 \pm 5.7^{\mathrm{ns}}$ & $30.43 \pm 1.6^{\mathrm{ns}}$ & $30.95 \pm 1.5^{\mathrm{ns}}$ & $8.98 \pm 0.5^{\mathrm{ns}}$ & $2.45 \pm 0.3^{\mathrm{ns}}$ \\
\hline \multirow{5}{*}{$\mathrm{T}_{2}$} & WT & $10.81 \pm 0.9$ & $28.12 \pm 1.8$ & $48.59 \pm 3.88$ & $1.90 \pm 0.2$ & $147 \pm 13$ & $88.62 \pm 6.5$ & $29.72 \pm 1.5$ & $31.21 \pm 1.8$ & $8.95 \pm 0.5$ & $2.39 \pm 0.3$ \\
\hline & GXU43_2 & $10.63 \pm 0.5^{\mathrm{ns}}$ & $26.63 \pm 1.9^{\mathrm{ns}}$ & $39.84 \pm 2.69 * *$ & $1.75 \pm 0.3^{\mathrm{ns}}$ & $146 \pm 11^{\mathrm{ns}}$ & $93.30 \pm 5.4^{\mathrm{ns}}$ & $29.96 \pm 1.7^{\mathrm{ns}}$ & $32.44 \pm 1.9^{\mathrm{ns}}$ & $8.27 \pm 0.3^{\mathrm{ns}}$ & $2.33 \pm 0.2^{\mathrm{ns}}$ \\
\hline & GXU43_4 & $9.71 \pm 0.7^{\mathrm{ns}}$ & $25.55 \pm 2.1^{\mathrm{ns}}$ & $38.23 \pm 2.52 * *$ & $1.65 \pm 0.5^{\mathrm{ns}}$ & $149 \pm 12^{\mathrm{ns}}$ & $90.95 \pm 6.2^{\mathrm{ns}}$ & $30.42 \pm 1.3^{\mathrm{ns}}$ & $31.77 \pm 1.5^{\mathrm{ns}}$ & $8.06 \pm 0.5^{\mathrm{ns}}$ & $2.29 \pm 0.3^{\mathrm{ns}}$ \\
\hline & GXU43_9 & $10.29 \pm 0.8^{n s}$ & $26.88 \pm 1.3^{\mathrm{ns}}$ & $36.70 \pm 2.58 * *$ & $1.55 \pm 0.2^{\mathrm{ns}}$ & $150 \pm 12^{\mathrm{ns}}$ & $92.51 \pm 6.9^{n s}$ & $30.88 \pm 2.1^{\mathrm{ns}}$ & $32.56 \pm 1.7^{\mathrm{ns}}$ & $8.87 \pm 0.7^{\mathrm{ns}}$ & $2.48 \pm 0.3^{\mathrm{ns}}$ \\
\hline & GXU43_19 & $10.85 \pm 0.6^{\mathrm{ns}}$ & $24.99 \pm 1.7^{\mathrm{ns}}$ & $39.73 \pm 2.85$ ** & $1.71 \pm 0.3^{\mathrm{ns}}$ & $148 \pm 10^{\mathrm{ns}}$ & $91.43 \pm 6.6^{\mathrm{ns}}$ & $29.54 \pm 1.9^{\mathrm{ns}}$ & $31.73 \pm 1.6^{\mathrm{ns}}$ & $8.61 \pm 0.6^{\mathrm{ns}}$ & $2.38 \pm 0.4^{\mathrm{ns}}$ \\
\hline \multirow{5}{*}{$\mathrm{T}_{3}$} & WT & $10.50 \pm 0.8$ & $27.96 \pm 1.6$ & $50.97 \pm 3.39$ & $1.85 \pm 0.1$ & $146 \pm 12$ & $86.85 \pm 5.9$ & $30.14 \pm 1.3$ & $31.96 \pm 2.6$ & $8.34 \pm 0.7$ & $2.27 \pm 0.2$ \\
\hline & GXU43_2 & $10.90 \pm 0.3^{\mathrm{ns}}$ & $27.41 \pm 1.3^{\mathrm{ns}}$ & $40.63 \pm 2.40^{* *}$ & $1.67 \pm 0.2^{\mathrm{ns}}$ & $149 \pm 10^{\mathrm{ns}}$ & $90.10 \pm 6.1^{\mathrm{ns}}$ & $30.33 \pm 1.8^{\mathrm{ns}}$ & $31.15 \pm 1.3^{\mathrm{ns}}$ & $8.45 \pm 0.5^{\mathrm{ns}}$ & $2.31 \pm 0.3^{\mathrm{ns}}$ \\
\hline & GXU43_4 & $10.77 \pm 0.5^{\mathrm{ns}}$ & $24.86 \pm 1.5^{\mathrm{ns}}$ & $41.33 \pm 2.13 * *$ & $1.76 \pm 0.3^{\mathrm{ns}}$ & $147 \pm 11^{\mathrm{ns}}$ & $92.33 \pm 5.8^{\mathrm{ns}}$ & $29.92 \pm 1.7^{\mathrm{ns}}$ & $30.49 \pm 1.2^{\mathrm{ns}}$ & $8.62 \pm 0.4^{\mathrm{ns}}$ & $2.42 \pm 0.4^{\mathrm{ns}}$ \\
\hline & GXU43_9 & $10.45 \pm 0.6^{\mathrm{ns}}$ & $24.18 \pm 1.9^{\mathrm{ns}}$ & $38.40 \pm 2.15^{* *}$ & $1.62 \pm 0.1^{\mathrm{ns}}$ & $150 \pm 09^{\mathrm{ns}}$ & $93.44 \pm 5.3^{\mathrm{ns}}$ & $30.50 \pm 2.2^{\mathrm{ns}}$ & $31.85 \pm 1.4^{\mathrm{ns}}$ & $8.50 \pm 0.6^{\mathrm{ns}}$ & $2.41 \pm 0.4^{\mathrm{ns}}$ \\
\hline & GXU43_19 & $10.99 \pm 0.4^{\mathrm{ns}}$ & $25.30 \pm 1.7^{\mathrm{ns}}$ & $39.33 \pm 2.50 * *$ & $1.59 \pm 0.3^{\mathrm{ns}}$ & $149 \pm 11^{\mathrm{ns}}$ & $89.03 \pm 5.7^{\mathrm{ns}}$ & $29.93 \pm 1.6^{\mathrm{ns}}$ & $31.29 \pm 1.5^{\mathrm{ns}}$ & $8.68 \pm 0.5^{\mathrm{ns}}$ & $2.36 \pm 0.3^{\mathrm{ns}}$ \\
\hline
\end{tabular}

Gen: Generation; WT: wild-type; PL: panicle length, PN: panicle numbers; FLW: flag leaf width, FLL: flag leaf length, GNPP: grain number per panicle; SSR: seed setting rate; GW: 1000-grain weight; YPP: yield per plant; GWD: grain width; GL: grain length. Mean data of three replicates. ${ }^{* *}$ represent the significant difference and ${ }^{\text {ns }}$ represents the non-significant difference at $p<0.01$. 


\subsection{Effect of Exogenous $\mathrm{GA}_{3}$}

We applied $10 \mu \mathrm{M} \mathrm{GA}_{3}$ to analyze the response of mutant and WT plants at the seedling stage. The data for plant height was recorded after 25 days. The mutant plants responded to exogenous $\mathrm{GA}_{3}$ significantly and restored the PH identically to that of the WT (Figure 3A,B). The homozygous mutant line GXU43_9 exhibited the lowest PH $(15.52 \mathrm{~cm})$ in controlled conditions as compared to the $\mathrm{PH}$ of wild type plants $(25.85 \mathrm{~cm})$, which was significantly higher than the mutant plants. Under the $\mathrm{GA}_{3}$ application, the $\mathrm{T}_{1}$ mutant line GXU43_9 restored the PH $(28.95 \mathrm{~cm})$, nearly equal to that of WT plants $(29.24 \mathrm{~cm})$. These results clearly show that the $\mathrm{GA}_{3}$ application promoted the growth of WT and mutant plants (Figure 3C).
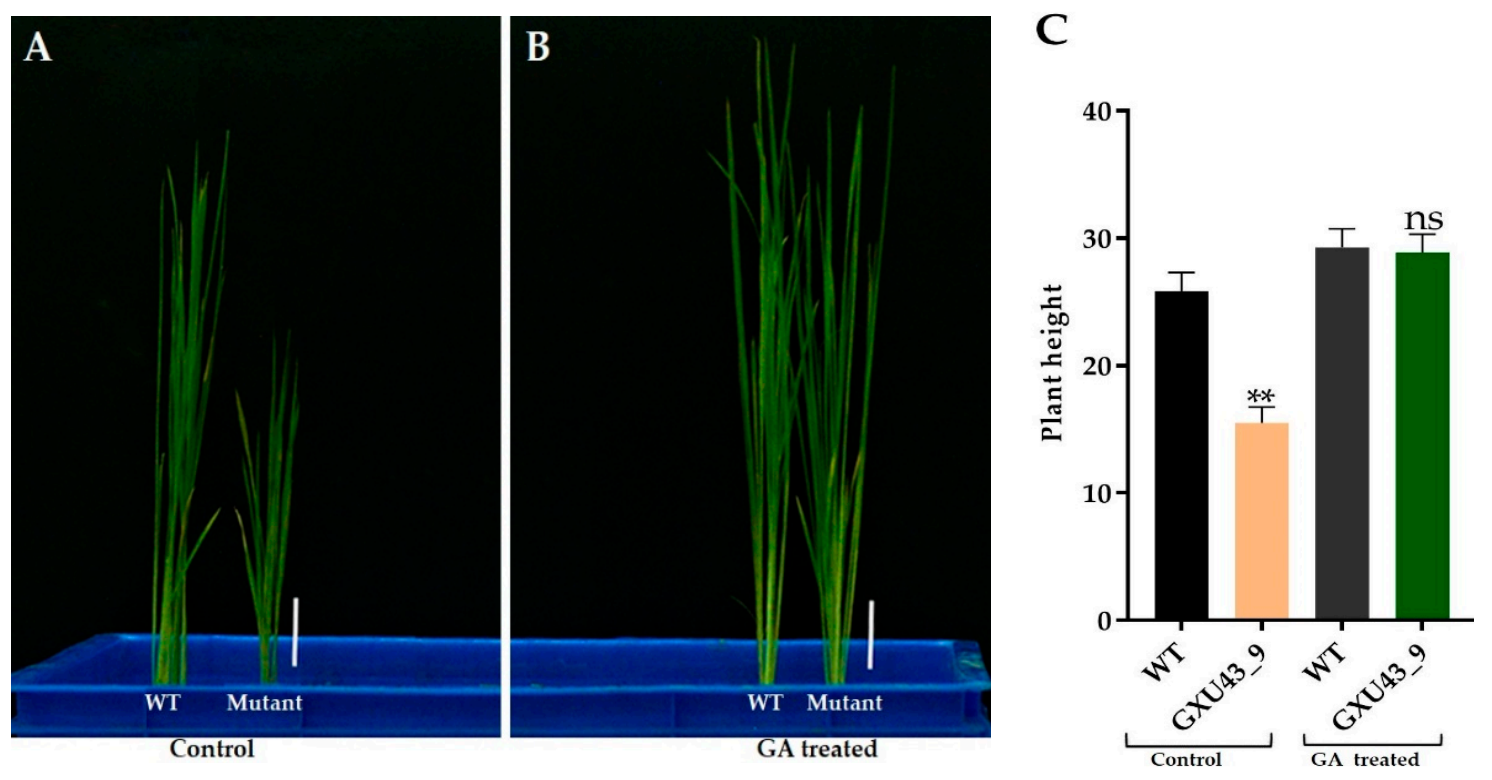

Figure 3. The seedling phenotype of the homozygous mutant GXU43_9 and WT. (A) Seedlings phenotype without GA, (B) Seedlings treated with GA, and (C) PH (plant height)of GA3-treated and control $(n=15)$, Bars $=3 \mathrm{~cm}$. Data are mean $\pm \mathrm{SD}$. “*** and "ns" represent a significant and non-significant difference respectively at $p \leq 0.01$.

\subsection{Section Analysis of Culm Cells}

The microscopic analysis of the culm cell of mutant line GXU43_9 showed irregularly shaped cells with thin walls, significantly smaller in size, and an increase in cell layers was observed as compared to WT (Figure 4A,B). From these results, we can conclude that the development of the stalk was affected in GXU43_9. The length and width of the cells in mutants was significantly smaller as compared to WT (Figure 4C,D). 

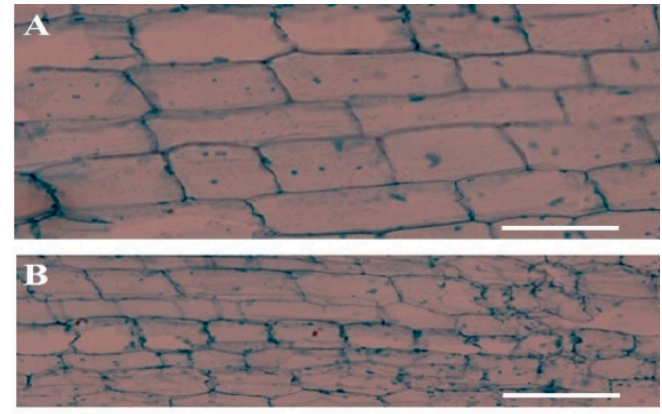

C

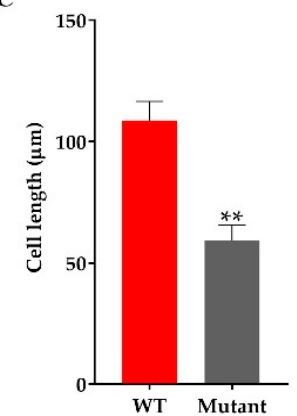

D

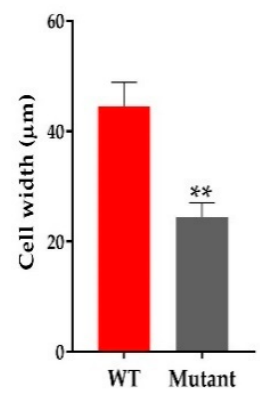

Figure 4. The microscopic analysis of culm cells of WT and mutant line GXU43_9. (A) WT second intermodal longitudinal length of the cell and (B) mutant plant GXU43_9, respectively. (C,D) Quantitative measurement of the length and width of the cells of mutant line (GXU43_9) and wild-type plants $(n=15)$, Bars $=100 \mu \mathrm{m}$. Data are the mean $\pm \mathrm{SD}$, “*** shows the significant difference at $p \leq 0.01$.

\subsection{Proteomics Analysis}

A total of 267,114 spectra was generated, and after the analysis of these spectra, we identified 68,489 known spectra with 24,230 peptides and 4003 proteins, respectively (Supplementary Figure S2A). The protein mass distribution is represented in Supplementary Figure S2B. The proteins having 20-40 kDa represented more protein numbers, and proteins with 141-150 kDa showed less protein numbers. The number of peptides identified in the proteins is shown in Supplementary Figure S2C. The information about the distribution of peptide length and protein sequence coverage is shown in Supplementary Figure S2D,E. After implementing the analysis with a minimum fold change (FC) of $\geq 1.2$ and $p$-value adjusted to $\leq 0.05$, a total of 588 DEPs ( 273 upregulated and 315 downregulated) were obtained (Figure 5A). The detailed information of all the proteins identified in this analysis is given in Supplementary file 2 .

A

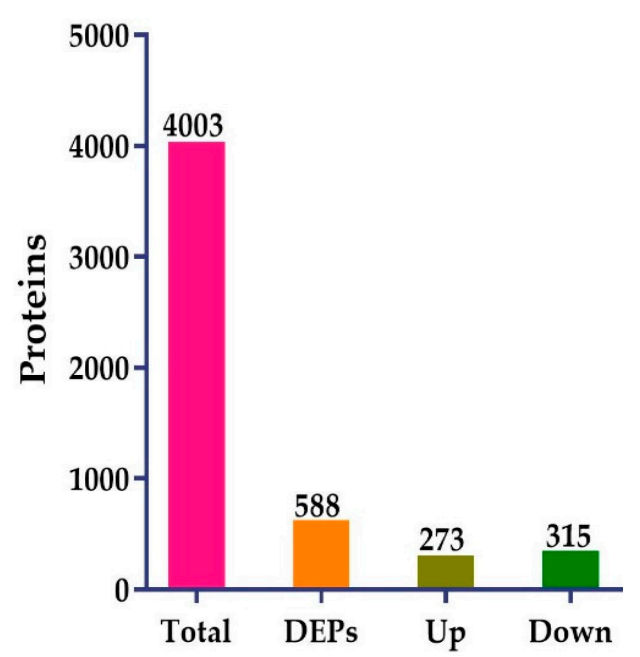

B

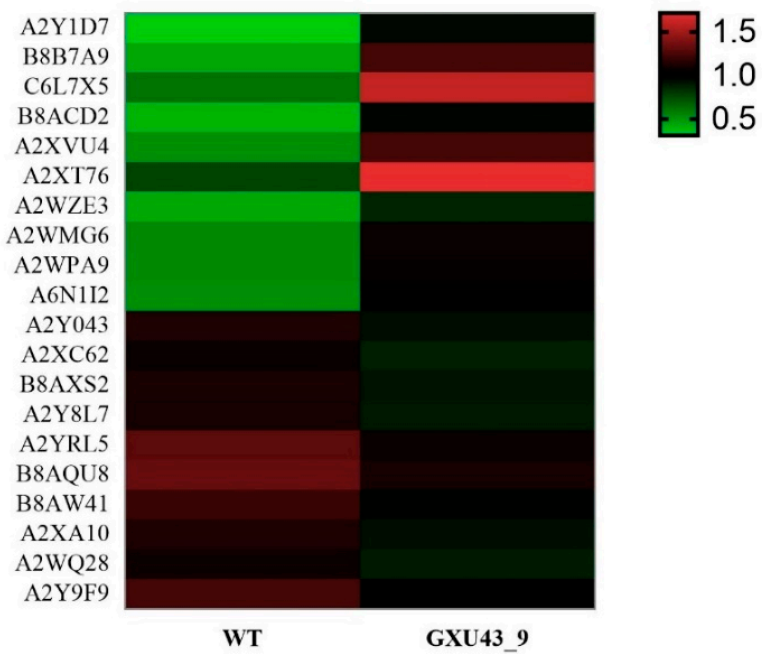

Figure 5. Proteomic analysis information of the CRISPR mutant GXU43_9 and its WT. (A) Upregulated and downregulated differentially expressed proteins (DEPs), and (B) Heatmap of the top twenty DEPs. Red color denotes the higher while the green color represents a lower level of expression.

The top 30 up- and down-regulated proteins were selected based on the highest log2 FC value, of which the top 10 upregulated DEPs were Metallothionein-like protein 3B (A2Y1D7), Uncharacterized protein (B8B7A9), Ethylene response factor (C6L7X5), Uncharacterized protein (B8ACD2), 
Uncharacterized protein (A2XVU4), Abscisic stress-ripening protein 5 (Q53JF7), Uncharacterized protein (A2WZE3), Salt stress root protein (A2WMG6), Peroxidase (A2WPA9), and ATP-dependent clp protease proteolytic subunit (A6N1I2). While the Peroxidase (A2Y043), Uncharacterized protein (A2XC62), Uncharacterized protein (B8AXS2), Peptidase A1 domain-containing protein (A2Y8L7), Growth-regulating factor 9 (Q9FRG8), MFS domain-containing protein (B8AQU8), NAD(P)-bd_dom domain-containing protein (B8AW41), Uncharacterized protein (A2XA10), Ent-copalyl diphosphate synthase 2 (Q5MQ85), and ATP-dependent 6-phosphofructokinase (A2Y9F9) were downregulated in the mutant line (Figure 5B).

We further searched the DEPs related to GA and plant growth. We found that five DEPs (Q6AWY7, Q6AWY2, Q9FRG8, Q6EPP9, and Q6AWX8) related to growth-regulating factors (GRF2, GRF7, GRF9, GRF10, and GRF11) were downregulated in this report. The DEPs related to gibberellin response modulator-like proteins (Q8RZ73 and Q9AS97), Chitin-inducible gibberellin-responsive proteins (Q69VG1 and Q339D4), Putative gibberellin oxidase (Q8LNJ6), Ent-copalyl diphosphate synthase 2 (Q5MQ85), gibberellin 20 oxidase 2 (Q0JH50), ATP synthase subunit beta chloroplastic (J7EYN3), and fructose-1,6-bisphosphatase, chloroplastic (A2XEX2) were also downregulated in mutant lines. However, the DEPs (Abscisic stress-ripening protein 5) and Q6I5C3 (Abscisic acid receptor) were upregulated in mutant plants (Table 3).

Table 3. Differentially expressed proteins related to GA and plant growth.

\begin{tabular}{|c|c|c|c|}
\hline Protein ID & Locus/Gene Name & Annotation & Regulate \\
\hline Q6AWY7 & Os06g0204800/GRF2 & Growth-regulating factor 2 & Down \\
\hline Q6AWY2 & Os12g0484900/GRF7 & Growth-regulating factor 7 & Down \\
\hline Q9FRG8 & Os03g0674700/GRF9 & Growth-regulating factor 9 & Down \\
\hline Q6EPP9 & Os02g0678800/GRF10 & Growth-regulating factor 10 & Down \\
\hline Q6AWX8 & Os07g0467500/GRF11 & Growth-regulating factor 11 & Down \\
\hline Q8RZ73 & B1065G12.22 & Gibberellin response modulator-like proteins & Down \\
\hline Q9AS97 & Os01g0646300 & Gibberellin response modulator-like & Down \\
\hline Q69VG1 & Os07g0545800/CIGR1 & Chitin-inducible gibberellin-responsive protein 1 & Down \\
\hline Q339D4 & LOC_Os10g22430 & Chitin-inducible gibberellin-responsive protein 2 & Down \\
\hline Q8LNJ6 & OSJNBb0028C01.33 & Putative gibberellin oxidase & Down \\
\hline Q0JH50 & Os01g0883800/GA20ox2 & Gibberellin 20 oxidase 2 & Down \\
\hline Q5MQ85 & CPS2 & Ent-copalyl diphosphate synthase 2 & Down \\
\hline P0C511 & RBCS & Ribulose bisphosphate carboxylase large chain & Down \\
\hline A2YQT7 & GAPC & Glyceraldehyde-3-phosphate dehydrogenase, cytosolic & Down \\
\hline Q6ZG90 & Os02g0131300 & ATP synthase & Down \\
\hline J7EYN3 & atpB & ATP synthase subunit beta, chloroplastic & Down \\
\hline A2XEX2 & OsI_10887 & Fructose-1,6-bisphosphatase, chloroplastic & Down \\
\hline C6L7X5 & Snorkel2 & Ethylene response factor & Down \\
\hline Q53JF7 & Os11g0167800/ASR5 & Abscisic stress-ripening protein & Up \\
\hline Q6I5C3 & Os05g0213500/PYL5 & Abscisic acid receptor & $\mathrm{Up}$ \\
\hline
\end{tabular}

\subsection{DEPs Functional Networks and Hub-Protein Analysis}

The STRING database was used for retrieving the protein interaction networks; for this purpose, the confidence (score) cutoff was adjusted to 50 with 30 additional interactors. The nodes represent the proteins, and protein-protein interaction (PPI) modes are shown by the lines among the nodes. The analysis of network revealed a higher co-expression between catalase isozyme B (Q0D9C4), 2-Cys peroxiredoxin BAS1 (Q6ER94), protein coleoptile photomorphogenesis 2 (Q75KD7), adenine phosphoribosyltransferase 1, putative, expressed (Q2QMV8), adenine phosphoribosyltransferase 1, putative (Q2QMT1), linoleate 9S-lipoxygenase 2 (P29250), lipoxygenase 7, chloroplastic (P38419), lipoxygenase (Q0IS17), linoleate 9S-lipoxygenase 1 (Q76I22), probable indole-3-acetic acid-amido synthetase (Q5NAZ7), isocitrate dehydrogenase (NADP) (Q7F280), and phloem sap $13 \mathrm{kDa}$ protein 1 (Q0D840), which showed a higher interaction score of $\geq 5$ (Figure 6A). 

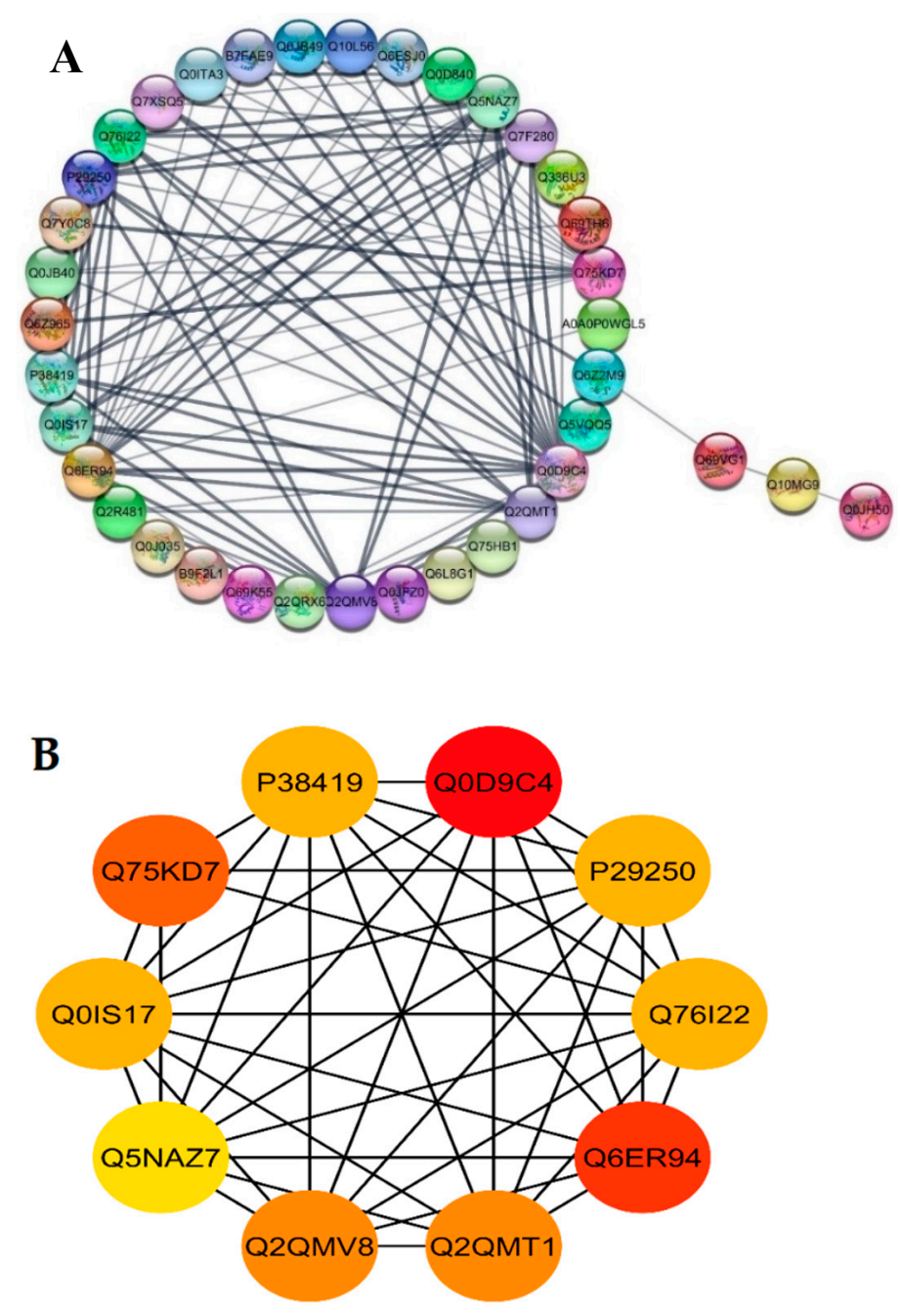

Figure 6. Functional networks of DEPs and hub-protein analysis of WT and mutant line GXU43_9. (A) STRING software predicted proteins' associations. The nodes represent differentially expressed proteins, while the edge denotes the interaction relationship between the nodes. (B) The top hub-proteins of WT and GXU43_9 comparison. The higher co-expression is denoted by red color.

Highly connected to 10 hub proteins with a higher degree of connectivity by the STRING database, the following were selected as candidate hub proteins: the adenine phosphoribosyltransferase 1, putative, expressed (Q2QMV8), adenine phosphoribosyltransferase 1 (Q2QMT1), linoleate 9S-lipoxygenase 2 (P29250), lipoxygenase 7, chloroplastic (P38419), lipoxygenase (Q0IS17), linoleate 9S-lipoxygenase 1 (Q76I22), probable indole-3-acetic acid-amido synthetase (Q5NAZ7), and 2-Cys peroxiredoxin BAS1, chloroplastic (Q6ER94) (Figure 6B).

\subsection{Gene Ontology (GO) and Pathway Enrichment Analysis}

GO annotations for DEPs related to BP (biological processes) were associated with the cellular process, metabolic process, cellular metabolic process, organic substance metabolic process, primary metabolic process, single-organism process, nitrogen compound metabolic process, biosynthetic process, single-organism cellular process, and cellular biosynthetic process. Proteins conferring CC (cellular components) were mainly involved in cell, cell part, intracellular (intracellular part, organelle, and membrane-bounded), organelle (primary and membrane-bounded), cytoplasm, and cytoplasmic part. Finally, for the MF (molecular functions) perspective, the DEPs took part in catalytic activity, oxidoreductase activity, RNA binding, tetrapyrrole binding, hydrolase activity (primary and cofactor binding), acting on acid anhydrides in phosphorus-containing anhydrides, 
acting on acid anhydrides structural molecule activity, pyrophosphatase activity, and structural constituent of ribosome (Figure 7A).

A

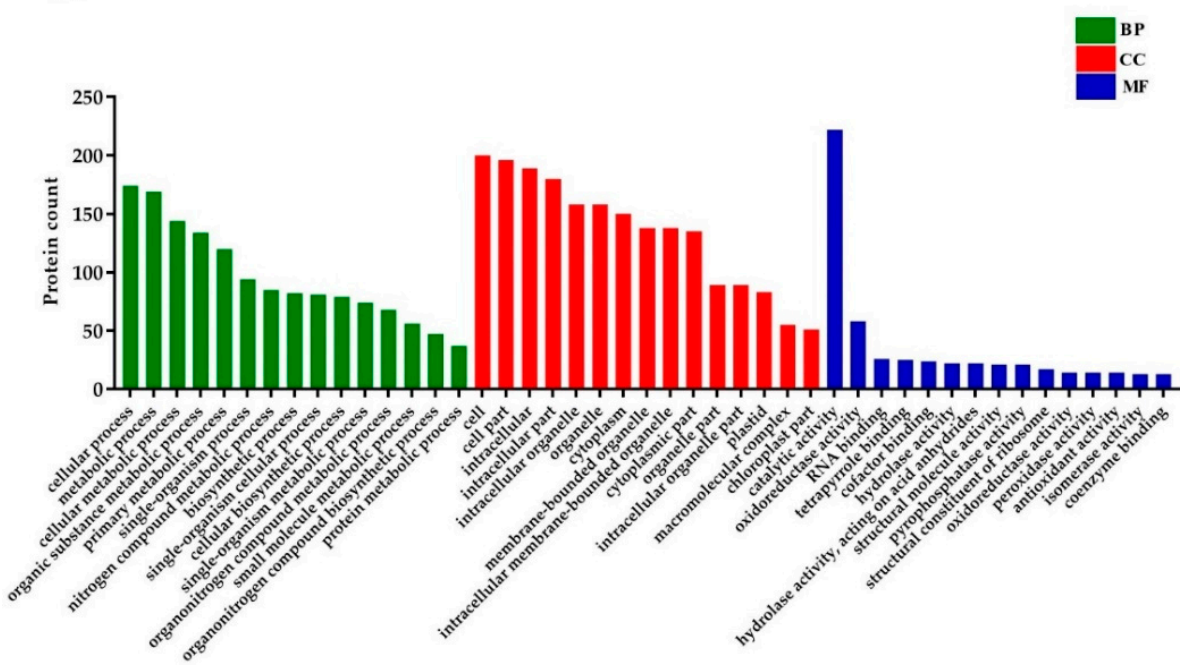

B

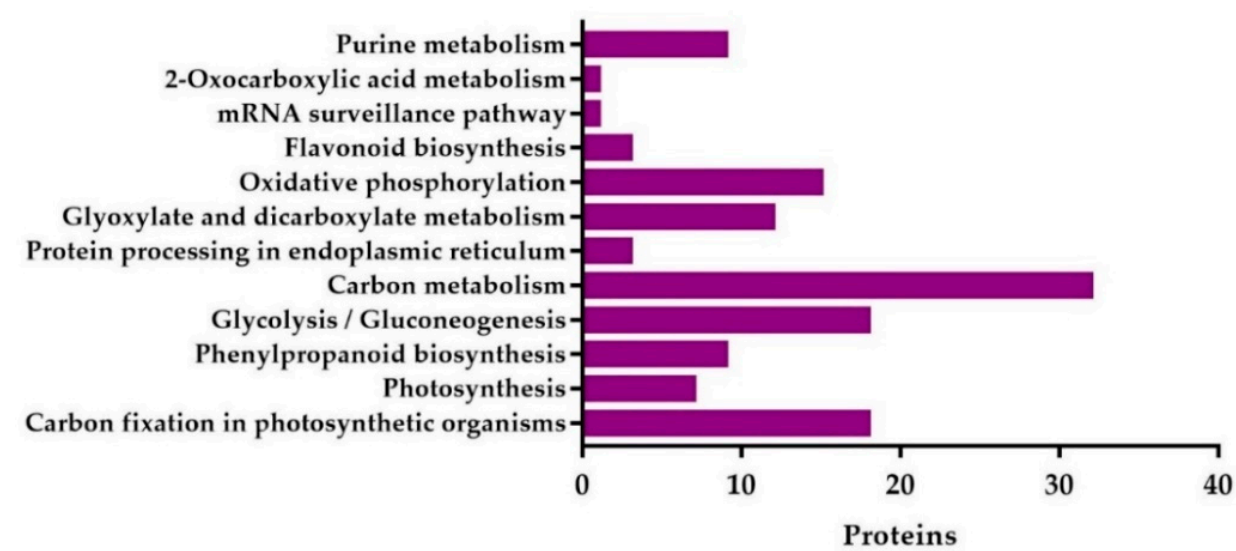

Figure 7. Gene ontology (GO) and KEGG (Kyoto Encyclopedia of Genes and Genomes) pathway enrichment analysis of DEPs. (A) GO annotations of the DEPs, and (B) the histogram of KEGG pathway enrichment, with the bar showing the number of proteins. BP; biological processes, CC; cellular components, and MF; molecular functions.

KEGG (Kyoto Encyclopedia of Genes and Genomes) pathway analysis uncovered that the DEPs were mostly enriched in carbon fixation in photosynthetic organisms, photosynthesis, phenylpropanoid biosynthesis, glycolysis/gluconeogenesis, protein processing in the endoplasmic reticulum, carbon metabolism, glyoxylate and dicarboxylate metabolism, oxidative phosphorylation, flavonoid biosynthesis, mRNA surveillance pathway, and 2-Oxocarboxylic acid metabolism (Figure 7B).

\subsection{RT-qPCR Analysis of Target Gene and Proteomic Data Validation}

The RT-qPCR was used to assess the relative expression of the OsGA20ox2 gene in mutants and WT plants. To normalize the expression, the Rice Actin gene was used as a reference between the samples, and the expression of OsGA20ox 2 was significantly suppressed in all mutant lines $(p<0.01$, Figure 8A). Ten genes associated with DEPs were selected for the validation of the proteomic data, and the qRT-PCR assay was performed for independent samples of WT and mutant lines. 
In total, eight key genes encoding downregulated DEPs, including GRF2, GRF7, ethylene response factor gene (Snorkel2), ribulose bisphosphate carboxylase small-chain gene (RBCS), ATP synthase subunit beta (atpB), Ent-copalyl diphosphate synthase 2 gene (CPS2), GRF10, and Chitin-inducible gibberellin-responsive protein1 (CIGR1), and two genes encoding upregulated DEPs, including abscisic stress-ripening protein 5 gene (ASR5) and Abscisic acid receptor (PYL5), were chosen. The level of expression of selected genes was consistent with the proteomic analysis (Figure 8B). Primers used for RT-qPCR are given in Supplementary file 1, Table S1.

A

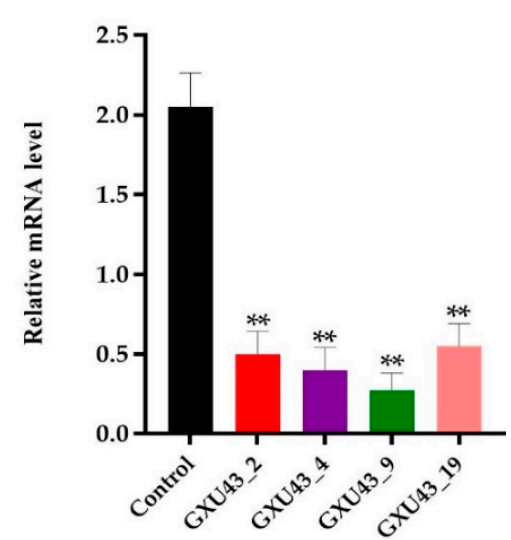

B

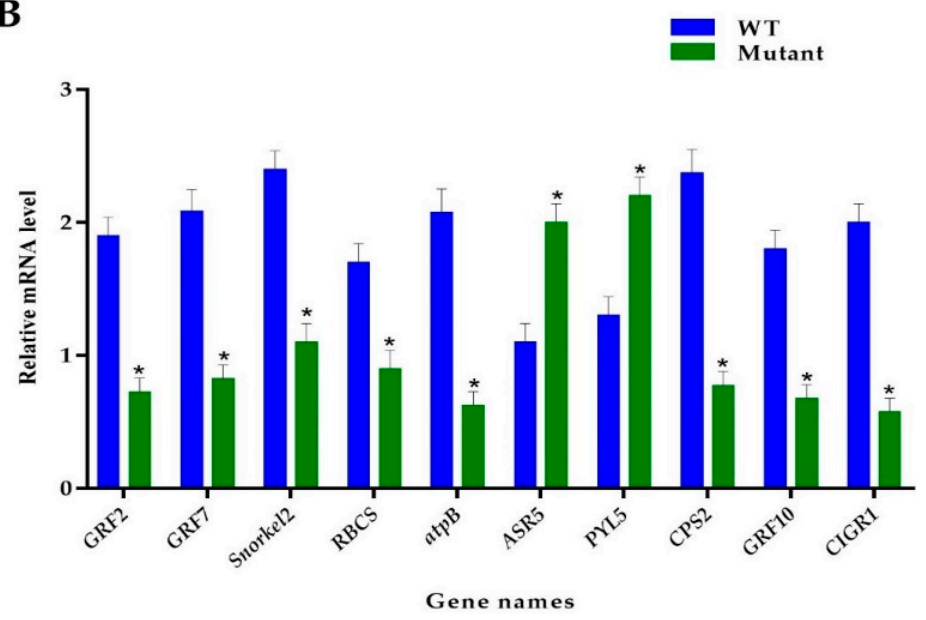

Figure 8. Real-time quantitative PCR assessment and validation of proteomics data. (A) Expression analysis of OsGA20ox2, in WT and $\mathrm{T}_{1}$ mutant lines, (B) RT qPCR validation of the ten DEPs responsive genes. The SD is shown with error bars, " "* represents the significant differences at $p \leq 0.05$ and “*** represents the significant differences at $p \leq 0.01$ respectively; $n=3$.

\section{Discussion}

The rise of modern molecular breeding technologies has provided fast and efficient means for plant breeding, which can directly modify desirable traits without changing and affecting other traits. CRISPR/Cas9 is determined by the easily and cheaply modified sgRNA (Single guided RNA) followed by a short PAM (protospacer adjacent motif) sequence to induce mutations with high accuracy and reduced probability of off-targets [53-55]. Crop improvement by using gene editing suggests decent prospects to generate mutants with preferred traits. However, there are very few examples of the utilization of SSNs (sequence-specific nucleases) for the generation of novel genotypes with desired plant type. The CRISPR/Cas9 technique has been extensively used in many species for the targeted mutagenesis because of its high efficiency. In this study, we have successfully used this system to edit the OsGA20ox2 gene with a higher mutation efficiency. Mutants are very important for genetic research and crop breeding. However, the assimilation of desired genes into elite breeding varieties is still a challenging task.

Breeding productivity is restricted by the continuous selection process, which is the main drawback of conventional breeding [56,57]. The natural selection events occur at random and result in unguided mutagenesis that brings a little frequency of, mutational events at target loci [57]. On the other hand, CRISPR technology has a great potential to produce mutants by the targeted mutagenesis in pre-decided locus [49]. We employed the iTRAQ strategy to confirm the effects of CRISPR-based gene editing at the whole proteome level.

The CRISPR/Cas9 vector has two key functional parts, including a gRNA and Cas9 expression cassettes, driven by RNA polymerase III and 35S/ubiquitin promoters, respectively. Because the Pol III has a limited transcriptional capacity, previously, researchers used U3/U6 promoters from rice, which have specific transcriptional sites with nucleotides A and G, respectively [58,59]. We used U6 (OsU6a, OsU6) promoters to construct the expression cassette, the target sequences were selected with 
5'-GN(19)NGG and, 5'-AN(19)NGG, respectively. Two sgRNAs were ligated successfully in the U6 promoters-driven expression cassette for targeting OsGA20ox2. In the present work, the CRISPR/Cas9 tool was used for editing the OsGA20ox2 gene in the Basmati rice line. The heterozygous and homozygous mutation events were found frequently, however, the chimeric mutations were rare. The homozygous and compound heterozygous mutations are also found frequently in previous studies $[60,61]$. The homozygous mutant plants achieved in $\mathrm{T}_{0}$ generation showed stable and inheritable mutations to the subsequent generations. In previously reported studies the homozygous mutations have also been achieved in $\mathrm{T}_{0}$ generation [61]. In this study, the mean mutation efficiency obtained was $70 \%$, and the mutant lines were obtained without any off-target mutations. The previously reported work also suggests that the Cas9 rarely tempts off-target mutations in rice [62,63], and we screened the T-DNA-free lines at a frequency of $40 \%$. The segregation and predicted inheritance have great importance in molecular breeding. In our study, we found inheritable and highly stable mutations induced by Cas9. In segregation analysis, the homozygous mutations were transmitted stably, showing no inversions or new mutations in $\mathrm{T}_{1}$ according to the Mendelian principle. Bi-allelic and heterozygous mutations were segregated at a 1:2:1 ratio, while the chimeric mutations were found to be unpredicted. We can conclude from the results that the new mutations are not induced by Cas9, while further experiments are needed to uncover the unpredictable segregations of chimeric mutations [61,64].

The GA biosynthesis and deactivation genes confer endogenous GA levels and response to GA metabolism [12,65-69]. Semi-dwarfism is a very important trait and rice varieties with this feature brought about significant improvements in grain production. GA is considered as the main plant growth-promoting hormone for triggering stem elongation, which experiences dynamic cell division for controlling plant development and growth [70]. The expression level of OsGA20ox2 was significantly reduced and mutant lines exhibited semi-dwarf $\mathrm{PH}$ at seedlings and mature stages, with significantly lowered GA content. Studies have revealed that $\mathrm{GA}_{3}$ promotes stem and sheath elongation and synthesis of many proteins related to plant growth [71-73]. The mutant plants restored their PH with exogenous $\mathrm{GA}_{3}$ application. The previous studies also showed that actual height similar to WT can be restored through $\mathrm{GA}_{3}$ treatment [74]. OsGA20ox2 CRISPR mutants also showed increased number and layers of cells, but decreased cell length and width, which may be the main cause of shortened PH. Dwarf plants usually show compact cell size and this results in affected cell expansion [75].

A total of 588 DEPs were identified in GXU43_9 versus the WT comparison, and among them, 273 were upregulated and 315 were downregulated, respectively. Some highly expressed proteins controlling PH were also identified in mutant lines. The DEPs including Q6AWY7, Q6AWY2, Q9FRG8, Q6EPP9, and Q6AWX8 (GRF2, 7, 9, 10, 11) were downregulated in mutant lines. In rice, the GRF family of TFs (transcription factors) has been previously identified [76], which are known as plant-specific TFs that were firstly known for their developmental role in leaf and stem growth [77]. OsGRF1 is a GA-induced gene in intercalary meristem internodes, and was the first GRF to be recognized in rice [78]. Some GRFs' expression level in Arabidopsis and rice is usually high in the tissues growing actively; besides, plants showed increased expression levels for several GRFs (OsGRFs 1, $2, \ldots 12$ ) after exogenous $\mathrm{GA}_{3}$ treatment, whereas OsGRF9 showed decreased expression [79-81]. OsGRF6 shows higher expression in developing inflorescences, which showed that GRFs are also involved in organ growth and development related to floral parts [82]. The gibberellin response modulator-like proteins (Q8RZ73 and Q9AS97), Chitin-inducible gibberellin-responsive proteins (Q69VG1 and Q339D4), Putative gibberellin oxidase (Q8LNJ6 and), Ent-copalyl diphosphate synthase 2 (Q5MQ85), gibberellin 20 oxidase 2 (Q0JH50), ATP synthase subunit beta chloroplastic (J7EYN3), fructose-1,6-bisphosphatase, chloroplastic (A2XEX2), and Ethylene response factor (C6L7X5) were also downregulated in mutant lines. Chitin-inducible GA responsive proteins (CIGR1 and CIGR2), inducible by the potent elicitor $\mathrm{N}$-acetylchitooligosaccharide (GN), are fast induced by exogenous $\mathrm{GA}$. The expression of proteins is reliant on the quantity and biological activity of GA, showing that the expression of these genes is mediated by GA [83]. Ent-copalyl-diphosphate act in the biosynthesis 
of defensive phytoalexin and GA phytohormone, which generally functions in GA biosynthesis, as mutations in the gene controlling this protein result in weakened growth [84]. Gibberellin 20 oxidase 2 is a major oxidase enzyme for the GA biosynthesis that is responsible for the catalyzation process which converts GA53 to GA20 through an oxidation reaction at C-20 of the GA skeleton and takes part in the internodal elongation [19].

Ribulose bisphosphate carboxylase (large and small chain) was downregulated in the mutant line and it was reported that RuBisco plays a significant role in the accumulation of chlorophyll and photosynthesis, and its overexpression leads to increased photosynthetic activity to attain growth [85]. The TPSs (terpene synthases) family is responsible for terpene molecules in plants, which play a key role in primary metabolism. In bryophyte, only a single TPS gene, CPS (copalyl synthase), is a precursor of GA, which encodes a bi-functional enzyme-producing ent-kaurene [86]. Loss-of-function mutants of SOTs (sulfotransferases) and TPST (tyrosylprotein SOTs) showed various abnormal characteristics due to peptides or proteins' sulfurization related to growth and development $[87,88]$. The TPST activity was previously observed in rice during microsomal membrane preparations [89]. The ethylene response factor (product of SNORKEL2) triggers notable internode elongation via gibberellin [90]. However, the DEPs, A2WPN7 (Salt stress-induced protein), A2WMG6 (Salt stress root protein), Q53JF7 (Abscisic stress-ripening protein 5), and Q615C3 (Abscisic acid receptor), were upregulated in mutant line GXU43_9 as compared to WT. Abscisic stress-ripening protein 5 was engaged in the GA signaling pathway and plant growth regulation in the region extending to basal leaf sheaths. The expression regulation of various genes is also carried out by ASR5 that contributes to cell protection against aluminum stress in rice plants [91]. In rice, the overexpression of PYL5 enhances abiotic stress tolerance and inhibits growth through gene expression modulation [92].

GO annotations of DEPs revealed that most of the proteins related to BP were associated with cellular and organic substance metabolic processes, the single-organism process, nitrogen compound metabolic process, and cellular biosynthetic process. Proteins conferring CC were associated with cell, cell part, intracellular (intracellular part, organelle, and membrane-bounded), organelle (primary and membrane-bounded), cytoplasm, and cytoplasmic part. Finally, for the MF perspective, the DEPs were mainly involved in catalytic activity, oxidoreductase activity, RNA binding, tetrapyrrole binding, cofactor binding hydrolase activity, hydrolase activity, pyrophosphatase activity, and structural constituent of ribosome. KEGG pathway analysis showed that the DEPs were enriched in carbon fixation in photosynthetic organisms, photosynthesis, and glycolysis/gluconeogenesis. In network analysis of hub-proteins, we found that most of the DEPs, including linoleate 9S-lipoxygenase 2, lipoxygenase 7, chloroplastic, lipoxygenase, and linoleate 9S-lipoxygenase 1 , were related to metabolic processes that may be engaged in various diverse aspects associated with plant physiology including growth and development $[93,94]$. In the present study, the proteins related to plant growth and GA were downregulated, implying that they may be responsible for a series of biochemical and physiological changes related to plant growth and ultimately affecting plant height. In summary, the plant height reduction through the modification of OsGA20ox2 expression levels in rice by affecting the biosynthesis of GA is potentially of great agronomic interest. This study showed that plant characteristics can be improved through genetic mutations. In this study, the successfully developed semi-dwarf mutant rice lines can be exploited for future breeding programs. Further studies regarding the cell signaling mechanisms owing to genome manipulations are warranted.

\section{Material and Methods}

\subsection{Material Used and Field Conditions}

Seeds of Basmati rice variety (VP-1643) were provided by the Wild Rice Group of Guangxi University (GXU) and plants were propagated in the experimental area of GXU, China, and at the Farm of Divisional Headquarters, Sanya Hainan, China, in the normal growing season and maintained consistently. The pYL CRISPR/Cas9Pubi- $H$ vector (Supplementary file 1, Figure S3) and the 
promoters (OsU6a and OsU6b) (Supplementary file 1, Figure S4A-C) were used to construct plasmid. This expression vector possesses the HPT selectable marker with a sequence bordering BsaI sites for sgRNA expression cassette insertion (Supplementary file 1, Figure S5A) [95].

\subsection{SgRNAs Selection, Vector Construction, and Transformation}

The target sequences were selected after the confirmation of $(N)_{20}$ GG or $G(N)_{20}$ GG template in coding regions of the OsGA20ox2 gene by employing the online website CRISPR-GE (http://skl.scau.edu.cn/) [96], with higher targeting specificity (Supplementary file 1, Table S5; Figure S5B). The two targets for OsGA20ox 2 were selected in the exon region from 128 to $147 \mathrm{bp}$ and 541 to $560 \mathrm{bp}$, respectively. The structures of all sgRNA's were developed by using an online tool, CRISPR-P (http://crispr.hzau.edu.cn/cgi-bin/CRISPR2/CRISPR) (Supplementary file 1, Figure S6). The overlapping PCR reaction was performed to construct the expression cassette [95] and is represented in Supplementary Figure S7, and the primers used are mentioned in Supplementary Table S1. The amplified product was purified by using TaKaRa MiniBEST Purification Kit Ver.4.0. The transformation of expression cassette to competent cells of E. coli DH5-alpha was performed according to a previously established method [97]. Primers SP-L1 and SP-R were used to assess the correct size of amplified products and sequenced directly (Supplementary file 1, Table S1). The sequences of target sites were confirmed in a constructed expression cassette. The order of U6 promoter-driven sgRNA cassettes was as follows: LacZ-OsU6a- $\mathrm{T}_{1}-\mathrm{OsU} 6 \mathrm{~b}-\mathrm{T}_{2}$ (Supplementary file 1, Figure S8A). The sizes of sgRNA cassettes after amplification were as follows: OsU6a-sgRNA1: 629 bp, OsU6b-sgRNA: 515 bp (Supplementary file 1, Figure S8B). After transforming the expression vector into competent cells of DH5 $\alpha$ the PCR amplification was performed to detect positive colonies (Supplementary file 1, Figure S8C). The sequence containing the target region of OsGA20ox2 in WT was amplified (Supplementary file 1, Figure S8D). Sequencing results successfully confirmed the targets assembly in the vector (Supplementary file 1, Figure S8E). The CRISPR/Cas9 binary vector was successfully constructed, which was considered suitable for rice transformation and target gene editing.

The transformation of embryonic calli was accomplished by the Agrobacterium tumefaciens-mediated co-cultivation method, as previously established by Hiei et al. [98].

\subsection{Genotyping, Off-Target Analysis, and Identification of Transgene-Free Plants}

The DNA extracted by the CTAB (cetyl trimethylammonium bromide) method [99] and target-specific primers (SD1T1 F/R and SD1T2 F/R) were designed for the amplification of both target sites of OsGA20ox2 gene (Supplementary file 1, Table S1). Sequences were decoded with DSDecode (http://skl.scau.edu.cn/dsdecode/) [100]. The CRISPR-GE online tool (http://skl.scau.edu.cn/) was accessed for the identification of the off-target sites (Supplementary file 1, Table S3) for the target regions, and five putative off-targets having $\geq 2$ nucleotide mismatches for each target site were tested. The primers were designed, and PCR products were sequenced directly (Supplementary file 1, Table S6). The genomic DNA in $\mathrm{T}_{1}$ and $\mathrm{T}_{2}$ (T-DNA-free and T-DNA) was extracted for genotyping and to study the inheritance patterns. The screening of T-DNA-free plants was performed by Cas9-F/Cas9-R and HPT-F/HPT-R primers in the $\mathrm{T}_{1}$ generation. Those plants regarded as T-DNA-free which lack both HPT and Cas9 simultaneously. The T-DNA-free homozygous mutant plants were further analyzed to study different agronomic and biochemical parameters. The mutations transmission patterns were studied for three consecutive generations by following the strict self-pollination of mutant lines. Segregation analysis was performed in $\mathrm{T}_{1}$ generation for T-DNA-free mutant lines. We conducted the chi-square test for the confirmation of the Mendelian inheritance.

\subsection{Phenotyping and Quantification of $G A_{3}$}

The data of major agronomic traits included: $\mathrm{PH}$ (plant height), PN (number of panicles), PL (length of panicle), SSR (rate of seed setting rate), GNPP (number of grain per panicle), FLW (width of flag leaf), FLL (length of flag leaf), GL (grains length), GW (1000-grain weight), GWD (grain width), and YPP 
(yield per plant). Endogenous GA levels were measured as previously described [75]. The measurement results were represented in $\mu \mathrm{g} / \mathrm{kg}$ FW according to standard methods [101], with three replicates.

\subsection{Microscopic Analysis and Application of $G A_{3}$}

Longitudinal sections of $0.5 \mathrm{~cm}$ taken from second internodes of mutant and WT mature plants and stained by using calcofluor and crystal violet and anatomical observations were done as described previously [102]. Slices were placed on slides in longitudinal sections and the results were analyzed by a Zeiss Axio Scope A1 Microscope. After 7 days of germination, the aqueous solution of $\mathrm{GA}_{3}$ with $10 \mu \mathrm{M}$ concentration was applied by spraying on seedlings, with an equal quantity of pure water used as a control, and the plant height was recorded after 25 days.

\subsection{Extraction, Digestion, and iTRAQ Labeling of Proteins}

Proteins were extracted from $100 \mathrm{mg}$ leaf samples of WT (VP-1643) and its CRISPR mutant GXU43_9, with three replicates, by grinding into liquid nitrogen, and immediately transferred to pre-cooled acetone $\left(-20^{\circ} \mathrm{C}\right)$, having $65 \mathrm{mM}$ dithiothreitol (DTT), and 10\% $(v / v)$ TCA (trichloroacetic acid) was added and mixed thoroughly, precipitated $\left(2 \mathrm{~h}\right.$ at $\left.-20^{\circ} \mathrm{C}\right)$, and centrifuged $(16,000 \times g$ for $30 \mathrm{~min}$ at $4^{\circ} \mathrm{C}$ ). Supernatant was carefully removed, and the pellet was washed thrice with $20 \mathrm{~mL}$ pre-cooled acetone. It was centrifuged $\left(20,000 \times g\right.$ at $\left.4{ }^{\circ} \mathrm{C}\right)$ and kept for half an hour at $-20{ }^{\circ} \mathrm{C}$. The precipitate was vacuum-dried soon after collection and the pellets obtained were fused with SDT containing 4\% SDS, $100 \mathrm{mM}$ Tris- $\mathrm{HCl}, 100 \mathrm{mM}$ DTT, pH 8.0, boiled for $5 \mathrm{~min}$, and then sonicated. The resultant product was centrifuged and filtered via a $0.22 \mu \mathrm{m}$ Millipore filter. The concentration of proteins in the lysate was measured by using a bicinchoninic acid (BCA) assay kit (Beyo time Institute of Biotechnology, Shanghai, China). The extracted proteins were digested by following the FASP (filter-aided sample preparation) procedure [103]. iTRAQ labeling was conducted by using iTRAQ Reagents 8PLEXKit (Applied Biosystems, Foster City, CA, USA), according to the directions of the manufacturers. Peptides were labeled with iTRAQ tags as (GXU43_9)-114 and (WT1643)-115 and were combined and vacuum-dried at room temperature.

\subsection{High-pH Reversed-phased Chromatography Separation}

The fractionation of peptides was accomplished in a 1100 Series HPLC (high-performance liquid chromatography) System with a well-equipped Gemini-NX (Phenomenex, Torrance, CA, USA 00F-4453-E0) column $(3 \mu \mathrm{m}, 110 \AA, 4.6 \times 150 \mathrm{~mm})$. The flow rate of $0.8 \mathrm{~mL} / \mathrm{min}$ was maintained for the peptide's elution. The composition of Buffer A was $10 \mathrm{mM}$ mmonium acetate, and buffer B was $10 \mathrm{mM}$ Ammonium acetate with a $90 \% v / v$ concentration of $\mathrm{CAN}$ and $\mathrm{pH}$ of 10 , respectively. The gradient separation was used as follows: for $40 \mathrm{~min}, 100 \%$ buffer $\mathrm{A}, 3 \mathrm{~min}$ with $0-5 \%$ buffer B, 30 min with 5-35\% buffer B, 10 min with 35-70\% buffer B, 10 min with 70-75\% buffer B, 7 min with 75-100\% buffer B, 15 min with $100 \%$ buffer B, and finally, 15 min with 100\% buffer A, and the absorbance was assessed at $214 \mathrm{~nm}$. For every sample, 20 fractions were taken and merged to get ten fractions. After the vacuum centrifugation, fractions were reconstituted by trifluoroacetic $40 \mu \mathrm{L}$ at a concentration of $0.1 \% v / v$. The samples were stored at $-80^{\circ} \mathrm{C}$ until LC-MS/MS analysis.

\subsection{LC-MS/MS Analysis}

To analyze the peptides, an easy-nLC 1000 HPLC system attached to an Orbitrap Elite mass spectrometer (Thermo Fisher Scientific, San Jose, CA, USA) was used. The samples were loaded on the Thermo Scientific EASY column with an autosampler at $150 \mathrm{~nL} / \mathrm{min}$. Peptides separation was carried out by using a C18 trap column (inner diameter $100 \mu \mathrm{m} \times 2 \mathrm{~cm}$ ) and a C18 analytical column (inner diameter $75 \mu \mathrm{m} \times 25 \mathrm{~cm})$. After $120 \mathrm{~min}$, segmented gradient ran with Buffer A $(0.1 \%$ formic acid in water) to $35 \%$ Buffer B (0.1\% formic acid in 100\% ACN) for 100 min, followed by 35-90\% Buffer B for $4 \mathrm{~min}$, and finally, 90\% Buffer B for $6 \mathrm{~min}$. The MS was conducted at a high-resolution mode (60K), with MS scans ranging between 300 and $2000 \mathrm{~m} / \mathrm{z}$, and 20 signals were acquired from the MS 
spectra according to the abundance for MS/MS analysis. DDA (data-dependent acquisition) and HCD (higher-energy collisional dissociation) were exploited with a medium resolution (15K) in MS/MS. $50 \mathrm{~ms}\left(10 \times 10^{-6}\right)$ was the uppermost ion injection time, which was utilized for the survey scanned at $150 \mathrm{~ms}\left(5 \times 10^{4}\right)$ for the MS/MS scans respectively, while the duration of the dynamic exclusion was $30 \mathrm{~s}$.

\subsection{Data Analysis}

We used Statistical Software Program SPSS 16.0 to analyze the data related to agronomic traits. Proteome Discoverer 2.1 was utilized for proteomics analysis against the Rice database (Oryza sativa subsp. Indica) on 17 September 2018, with 40,869 entries, by using the default parameters. Peptides with a global false discovery rate (FDR) $<1 \%$ were used for further protein annotation. The DEPs were functionally annotated by the GO database (http://www.geneontology.org/) and Blast2go software (http://www.blast2go.com/b2ghome) and proteins were grouped according to their participation in the $\mathrm{BP}, \mathrm{CC}$, and MF. The DAPs (differentially accumulated proteins) were further assigned to the KEGG (http://www.genome.jp/kegg/pathway) database. Fisher's Exact Test was used to identify the enriched GO terms and cluster analysis was performed by using Cluster 3.0 software. The pathways with FDR-corrected $p$-values $\leq 0.05$ were regarded as significant. The PPI was evaluated by the STRING (http://string-db.org/) database and hub-proteins were assessed by Cytoscape (version 3.7.2).

\subsection{Target Gene Expression Analysis and Proteomic Data Validation}

We took 30-day-old rice seedlings and the panicle tissues for RNA extraction. RT-qPCR, performed on Real-Time LC480 (Roche Applied Science, Penzberg, Germany), polymerase chain reaction (PCR), was carried out by $10 \mu \mathrm{L}$ volume with $0.08 \mu \mathrm{M}$ primers, a $0.3 \mu \mathrm{L}$ of reversed-transcribed product, and $5 \mu \mathrm{L}$ of ChamQTM Universal SYBR qPCR Master Mix (Vazyme Biotech Co.,Ltd, Nanjing, China). The Rice Actin gene used as an internal control to normalize the reaction and the primers used are listed in Supplementary file 1, Table S1, and the comparative expression was evaluated by the $2^{-\Delta \Delta} \mathrm{CT}$ method, as established earlier [104].

\section{Conclusions}

In conclusion, we have explored that the guided mutations of OsGA20ox2 through the CRISPR/Cas9 system is an effective strategy to develop semi-dwarf rice plants for sustainable production. Combining CRISPR/Cas9 and comprehensive proteomic analysis revealed new clues that will facilitate the understanding of the complex cellular and molecular events for important traits. In this study, fundamental resources are provided for identifying phytohormones, and some novel candidate proteins and metabolic pathways were found that could be involved in rice semi-dwarfism. The proteins crucial for various steps of GA and chlorophyll synthesis pathways were significantly repressed in semi-dwarf mutant lines. The results of this work revealed that the CRISPR/Cas9 technology is a very effective tool for the targeted gene editing, and these findings will contribute to an increased understanding of rice semi-dwarfism, and the generated mutant lines can be useful source material for future rice breeding programs.

Supplementary Materials: The following are available online at http://www.mdpi.com/1422-0067/21/17/6170/s1: Table S1: All the primers used in this study; Table S2: Type of mutations obtained in $\mathrm{T}_{0}$ generation by two constructs of CRISPR/Cas9; Table S3: Mutations detection on the potential off-targets; Table S4: Segregation of mutations induced by CRISPR/Cas9 in target genes; Table S5: Positions and efficiency score of both the targets; Table S6: List of primers utilized for analyzing off-targets. Figure S1: PCR amplification of CRISPR/Cas9 T-DNA integration; Figure S2: Analysis of the proteome of wild type (WT) and CRISPR/Cas9 mutants of rice.; Figure S3: Structure of $\mathrm{pYLCRISPR/Cas9Pubi-} H$ binary vector with fragment containing a modified ccdB flanked by two BsaI sites; Figure S4: Embedded view of plasmids; Figure S5: Schematic diagram of Vector map and sgRNA target sites in OsGA200x2; Figure S6: Schematic representation of secondary structures; Figure S7: Illustration of overlapping PCR for generation of expression cassette; Figure S8: Detection and amplification of CRISPR/Cas9 T-DNA integration and the OsGA20ox2 target sequence assembly in vector. 
Author Contributions: Conceptualization, G.N.; Data curation, G.N. and B.U.; Formal analysis, G.N. and B.U.; Funding acquisition, R.L.; Investigation, G.N., B.U., N.Z., and Z.L.; Methodology, G.N., N.Z., Y.H., Z.L., and X.W.; Project administration, R.L.; Resources, Y.L. and R.L.; Software, G.N. and B.U.; Supervision, R.L.; Validation, G.N.; Visualization, Y.L. and R.L.; Writing—original draft, G.N. and B.U.; Writing-review and editing, G.N. All authors have read and agreed to the published version of the manuscript.

Funding: This study was supported by the State Key Laboratory for Conservation and Utilization of Subtropical Agro-Bioresources (SKLCUSA-a201914).

Acknowledgments: We would like to thank Muhammad Haneef Kashif for the helpful discussion and invaluable comments to make this research meaningful.

Conflicts of Interest: The authors declare no conflict of interest.

\section{References}

1. Chandler, V.L.; Wessler, S. Grasses. A Collective Model Genetic System; American Society of Plant Biologists: Rockville, MD, USA, 2001.

2. Demont, M.; Stein, A. Global value of GM rice: A review of expected agronomic and consumer benefits. New Biotechnol. 2013, 30, 426-436. [CrossRef] [PubMed]

3. Khush, G.S. What it will take to Feed 5.0 Billion Rice consumers in 2030. Plant Mol. Biol. 2005, 59, 1-6. [CrossRef] [PubMed]

4. Sasaki, T.; Burr, B. International Rice Genome Sequencing Project: The effort to completely sequence the rice genome. Curr. Opin. Plant Biol. 2000, 3, 138-142. [CrossRef]

5. Singh, V.; Siddiq, E.; Zaman, F.; Sadananda, A. Improved Basmati Donors [Rice Varieties; India]; International Rice Research Newsletter: Los Baños, Philippines, 1988.

6. Singh, A.K.; Gopalakrishnan, S.; Singh, V.P.; Prabhu, K.V.; Mohapatra, T.; Singh, N.K.; Sharma, T.R.; Nagarajan, M.; Vinod, K.K.; Singh, D.; et al. Marker assisted selection: A paradigm shift in Basmati breeding. Indian J. Genet. Plant Breed. 2011, 71, 120-128.

7. Fischer, R.; Stapper, M. Lodging effects on high-yielding crops of irrigated semidwarf wheat. Field Crop. Res. 1987, 17, 245-258. [CrossRef]

8. Zhou, L.; Liu, S.; Wu, W.; Chen, D.; Zhan, X.; Zhu, A.; Zhang, Y.; Cheng, S.; Cao, L.; Lou, X.; et al. Dissection of genetic architecture of rice plant height and heading date by multiple-strategy-based association studies. Sci. Rep. 2016, 6, 29718. [CrossRef]

9. Yang, X.-C.; Hwa, C.-M. Genetic modification of plant architecture and variety improvement in rice. Heredity 2008, 101, 396-404. [CrossRef]

10. Sakamoto, T.; Matsuoka, M. Generating high-yielding varieties by genetic manipulation of plant architecture. Curr. Opin. Biotechnol. 2004, 15, 144-147. [CrossRef]

11. Zhang, J.; Liu, X.; Li, S.; Cheng, Z.; Li, C. The Rice Semi-Dwarf Mutant sd37, Caused by a Mutation in CYP96B4, Plays an Important Role in the Fine-Tuning of Plant Growth. PLoS ONE 2014, 9, e88068. [CrossRef]

12. Thomas, S.G.; Rieu, I.; Steber, C.M. Gibberellin Metabolism and Signaling. Vitam. Horm. 2005, 72, $289-338$. [CrossRef]

13. Monna, L.; Kitazawa, N.; Yoshino, R.; Suzuki, J.; Masuda, H.; Maehara, Y.; Tanji, M.; Sato, M.; Nasu, S.; Minobe, Y. Positional Cloning of Rice Semidwarfing Gene, sd-1: Rice "Green Revolution Gene" Encodes a Mutant Enzyme Involved in Gibberellin Synthesis. DNA Res. 2002, 9, 11-17. [CrossRef] [PubMed]

14. Magome, H.; Nomura, T.; Hanada, A.; Takeda-Kamiya, N.; Ohnishi, T.; Shinma, Y.; Katsumata, T.; Kawaide, H.; Kamiya, Y.; Yamaguchi, S. CYP714B1 and CYP714B2 encode gibberellin 13-oxidases that reduce gibberellin activity in rice. Proc. Natl. Acad. Sci. USA 2013, 110, 1947-1952. [CrossRef] [PubMed]

15. Marciniak, K.; Kućko, A.; Wilmowicz, E.; Świdziński, M.; Kęsy, J.; Kopcewicz, J. Photoperiodic flower induction in Ipomoea nil is accompanied by decreasing content of gibberellins. Plant Growth Regul. 2017, 84, 395-400. [CrossRef]

16. Thomas, S.G.; Hedden, P.; Roberts, J.A.; Evan, D.; McManus, M.T.; Rose, J.K.C. Gibberellin Metabolism and Signal Transduction. Annu. Plant Rev. Online 2018, 147-184. [CrossRef]

17. Itoh, H.; Tatsumi, T.; Sakamoto, T.; Otomo, K.; Toyomasu, T.; Kitano, H.; Ashikari, M.; Ichihara, S.; Matsuoka, M. A Rice Semi-Dwarf Gene, Tan-Ginbozu (D35), Encodes the Gibberellin Biosynthesis Enzyme, ent-Kaurene Oxidase. Plant Mol. Biol. 2004, 54, 533-547. [CrossRef] [PubMed] 
18. Sasaki, A.; Ashikari, M.; Ueguchi-Tanaka, M.; Itoh, H.; Nishimura, A.; Swapan, D.; Ishiyama, K.; Saito, T.; Kobayashi, M.; Khush, G.S.; et al. A mutant gibberellin-synthesis gene in rice. Nature 2002, 416, 701-702. [CrossRef]

19. Spielmeyer, W.; Ellis, M.H.; Chandler, P.M. Semidwarf (sd-1), "green revolution" rice, contains a defective gibberellin 20-oxidase gene. Proc. Natl. Acad. Sci. USA 2002, 99, 9043-9048. [CrossRef]

20. Qiao, F.; Zhao, K.-J. The Influence of RNAi Targeting of OsGA20ox2 Gene on Plant Height in Rice. Plant Mol. Biol. Rep. 2011, 29, 952-960. [CrossRef]

21. Wu, B.; Hu, W.; Ayaad, M.; Liu, H.; Xing, Y. Intragenic recombination between two non-functional semi-dwarf 1 alleles produced a functional SD1 allele in a tall recombinant inbred line in rice. PLOS ONE 2017, 12, e0190116. [CrossRef]

22. Han, Y.; Teng, K.; Nawaz, G.; Feng, X.; Usman, B.; Wang, X.; Luo, L.; Zhao, N.; Liu, Y.; Li, R. Generation of semi-dwarf rice (Oryza sativa L.) lines by CRISPR/Cas9-directed mutagenesis of OsGA20ox2 and proteomic analysis of unveiled changes caused by mutations. 3 Biotech 2019, 9, 387. [CrossRef]

23. Qi, W.; Zhu, T.; Tian, Z.; Li, C.; Zhang, W.; Song, R. High-efficiency CRISPR/Cas9 multiplex gene editing using the glycine tRNA-processing system-based strategy in maize. BMC Biotechnol. 2016, 16, 58. [CrossRef] [PubMed]

24. Zheng, X.; Yang, S.; Zhang, Y.; Zhong, Z.; Tang, X.; Deng, K.; Zhou, J.; Qi, Y.; Zhang, Y. Effective screen of CRISPR/Cas9-induced mutants in rice by single-strand conformation polymorphism. Plant Cell Rep. 2016, 35, 1545-1554. [CrossRef] [PubMed]

25. Nawaz, G.; Usman, B.; Peng, H.; Zhao, N.; Yuan, R.; Liu, Y.-G.; Li, R. Knockout of Pi21 by CRISPR/Cas9 and iTRAQ-Based Proteomic Analysis of Mutants Revealed New Insights into M. oryzae Resistance in Elite Rice Line. Genes 2020, 11, 735. [CrossRef] [PubMed]

26. Jung, Y.-J.; Nogoy, F.M.; Lee, S.-K.; Cho, Y.-G.; Kang, K.-K. Application of ZFN for Site Directed Mutagenesis of Rice SSIVa Gene. Biotechnol. Bioprocess Eng. 2018, 23, 108-115. [CrossRef]

27. Gaj, T.; Gersbach, C.A.; Barbas, I.C.F. ZFN, TALEN and CRISPR/Cas-based methods for genome engineering. Trends Biotechnol. 2013, 31, 397-405. [CrossRef]

28. Jiang, W.; Zhou, H.; Bi, H.; Fromm, M.; Yang, B.; Weeks, D.P. Demonstration of CRISPR/Cas9/sgRNA-mediated targeted gene modification in Arabidopsis, tobacco, sorghum and rice. Nucleic Acids Res. 2013, 41, e188. [CrossRef]

29. Li, J.-F.; Norville, J.E.; Aach, J.; McCormack, M.; Zhang, D.; Bush, J.; Church, G.M.; Sheen, J. Multiplex and homologous recombination-mediated genome editing in Arabidopsis and Nicotiana benthamiana using guide RNA and Cas9. Nat. Biotechnol. 2013, 31, 688-691. [CrossRef]

30. Mao, Y.; Zhang, H.; Xu, N.; Zhang, B.; Gou, F.; Zhu, J.-K. Application of the CRISPR-Cas System for Efficient Genome Engineering in Plants. Mol. Plant 2013, 6, 2008-2011. [CrossRef]

31. Shan, Q.; Wang, Y.; Li, J.; Zhang, Y.; Chen, K.; Liang, Z.; Zhang, K.; Liu, J.; Xi, J.J.; Qiu, J.; et al. Targeted genome modification of crop plants using a CRISPR-Cas system. Nat. Biotechnol. 2013, 31, 686-688. [CrossRef]

32. Nawaz, G.; Han, Y.; Usman, B.; Liu, F.; Qin, B.; Li, R. Knockout of OsPRP1, a gene encoding proline-rich protein, confers enhanced cold sensitivity in rice (Oryza sativa L.) at the seedling stage. 3 Biotech 2019, 9, 1-18. [CrossRef]

33. Liang, Z.; Zhang, K.; Chen, K.; Gao, C. Targeted Mutagenesis in Zea mays Using TALENs and the CRISPR/Cas System. J. Genet. Genom. 2014, 41, 63-68. [CrossRef] [PubMed]

34. Wang, Y.; Cheng, X.; Shan, Q.; Zhang, Y.; Liu, J.; Gao, C.; Qiu, J. Simultaneous editing of three homoeoalleles in hexaploid bread wheat confers heritable resistance to powdery mildew. Nat. Biotechnol. 2014, 32, 947-951. [CrossRef] [PubMed]

35. Jacobs, T.B.; Lafayette, P.R.; Schmitz, R.J.; Parrott, W.A. Targeted genome modifications in soybean with CRISPR/Cas9. BMC Biotechnol. 2015, 15, 16. [CrossRef] [PubMed]

36. Li, Z.; Liu, Z.-B.; Xing, A.; Moon, B.P.; Koellhoffer, J.P.; Huang, L.; Ward, R.T.; Clifton, E.; Falco, S.C.; Cigan, A.M. Cas9-Guide RNA Directed Genome Editing in Soybean. Plant Physiol. 2015, 169, 960-970. [CrossRef]

37. Sun, X.; Hu, Z.; Chen, R.; Jiang, Q.; Song, G.; Zhang, H.; Xi, Y. Targeted mutagenesis in soybean using the CRISPR-Cas9 system. Sci. Rep. 2015, 5, 10342. [CrossRef] 
38. Brooks, C.; Nekrasov, V.; Lippman, Z.; Van Eck, J. Efficient Gene Editing in Tomato in the First Generation Using the Clustered Regularly Interspaced Short Palindromic Repeats/CRISPR-Associated9 System1. Plant Physiol. 2014, 166, 1292-1297. [CrossRef]

39. Xu, R.-F.; Li, H.; Qin, R.-Y.; Li, J.; Qiu, C.-H.; Yang, Y.-C.; Ma, H.; Li, L.; Wei, P.; Yang, J.-B. Generation of inheritable and "transgene clean" targeted genome-modified rice in later generations using the CRISPR/Cas9 system. Sci. Rep. 2015, 5, 11491. [CrossRef]

40. Kok, E.; Kuiper, H.A. Comparative safety assessment for biotech crops. Trends Biotechnol. 2003, 21, 439-444. [CrossRef]

41. Chassy, B.M. Food safety evaluation of crops produced through biotechnology. J. Am. Coll. Nutr. 2002, 21, 166-173. [CrossRef]

42. Brandão, A.; Barbosa, H.; Arruda, M. Image analysis of two-dimensional gel electrophoresis for comparative proteomics of transgenic and non-transgenic soybean seeds. J. Proteom. 2010, 73, 1433-1440. [CrossRef]

43. Wang, L.; Wang, X.; Jin, X.; Jia, R.; Huang, Q.; Tan, Y.; Guo, A. Comparative proteomics of Bt-transgenic and non-transgenic cotton leaves. Proteome Sci. 2015, 13, 1-15. [CrossRef]

44. Wang, Y.; Xu, W.; Zhao, W.; Hao, J.; Luo, Y.; Tang, X.; Zhang, Y.; Huang, K. Comparative analysis of the proteomic and nutritional composition of transgenic rice seeds with Crylab/ac genes and their non-transgenic counterparts. J. Cereal Sci. 2012, 55, 226-233. [CrossRef]

45. Yang, Y.; Chen, X.; Xu, B.; Li, Y.; Ma, Y.; Wang, G. Phenotype and transcriptome analysis reveals chloroplast development and pigment biosynthesis together influenced the leaf color formation in mutants of Anthurium andraeanum 'Sonate'. Front. Plant Sci. 2015, 6, 139. [CrossRef]

46. Hellinger, R.; Koehbach, J.; Soltis, U.E.; Carpenter, E.J.; Wong, G.K.-S.; Gruber, C.W. Peptidomics of Circular Cysteine-Rich Plant Peptides: Analysis of the Diversity of Cyclotides from Viola tricolor by Transcriptome and Proteome Mining. J. Proteome Res. 2015, 14, 4851-4862. [CrossRef]

47. Kamal, A.H.M.; Cho, K.; Choi, J.-S.; Bae, K.-H.; Komatsu, S.; Uozumi, N.; Woo, S.-H. The wheat chloroplastic proteome. J. Proteom. 2013, 93, 326-342. [CrossRef]

48. Wang, F.-X.; Luo, Y.-M.; Ye, Z.-Q.; Cao, X.; Liang, J.-N.; Wang, Q.; Wu, Y.; Wu, J.-H.; Wang, H.-Y.; Zhang, M.; et al. iTRAQ-based proteomics analysis of autophagy-mediated immune responses against the vascular fungal pathogen Verticillium dahliae in Arabidopsis. Autophagy 2018, 14, 598-618. [CrossRef]

49. Wang, J.; Islam, F.; Li, L.; Long, M.; Yang, C.; Jin, X.; Ali, B.; Mao, B.; Zhou, W. Complementary RNA-Sequencing Based Transcriptomics and iTRAQ Proteomics Reveal the Mechanism of the Alleviation of Quinclorac Stress by Salicylic Acid in Oryza sativa ssp. japonica. Int. J. Mol. Sci. 2017, 18, 1975. [CrossRef]

50. Liao, S.; Qin, X.; Luo, L.; Han, Y.; Wang, X.; Usman, B.; Nawaz, G.; Zhao, N.; Liu, Y.-G.; Li, R. CRISPR/Cas9-Induced Mutagenesis of Semi-Rolled Leaf1,2 Confers Curled Leaf Phenotype and Drought Tolerance by Influencing Protein Expression Patterns and ROS Scavenging in Rice (Oryza sativa L.). Agronomy 2019, 9, 728. [CrossRef]

51. Chen, S.; Chen, J.; Hou, F.; Feng, Y.; Zhang, R. iTRAQ-based quantitative proteomic analysis reveals the lateral meristem developmental mechanism for branched spike development in tetraploid wheat (Triticum turgidum L.). BMC Genom. 2018, 19, 228. [CrossRef]

52. Bu, T.-T.; Shen, J.; Chao, Q.; Shen, Z.; Yan, Z.; Zheng, H.-Y.; Wang, B.-C. Dynamic N-glycoproteome analysis of maize seedling leaves during de-etiolation using Concanavalin A lectin affinity chromatography and a nano-LC-MS/MS-based iTRAQ approach. Plant Cell Rep. 2017, 36, 1943-1958. [CrossRef]

53. Chen, L.; Wang, S.; Zhang, Y.-H.; Li, J.; Xing, Z.; Yang, J.; Huang, T.; Cai, Y.-D. Identify Key Sequence Features to Improve CRISPR sgRNA Efficacy. IEEE Access 2017, 5, 26582-26590. [CrossRef]

54. Sauer, N.J.; Narváez-Vásquez, J.; Mozoruk, J.; Miller, R.B.; Warburg, Z.; Woodward, M.J.; Mihiret, Y.A.; Lincoln, T.A.; Segami, R.E.; Sanders, S.L.; et al. Oligonucleotide-Mediated Genome Editing Provides Precision and Function to Engineered Nucleases and Antibiotics in Plants. Plant Physiol. 2016, 170, 1917-1928. [CrossRef]

55. Li, J.; Meng, X.; Zong, Y.; Chen, K.; Zhang, H.; Liu, J.; Li, J.; Gao, C. Gene replacements and insertions in rice by intron targeting using CRISPR-Cas9. Nat. Plants 2016, 2, 16139. [CrossRef]

56. Soyk, S.; Lemmon, Z.H.; Oved, M.; Fisher, J.; Liberatore, K.L.; Park, S.J.; Goren, A.; Jiang, K.; Ramos, A.; Van Der Knaap, E.; et al. Bypassing Negative Epistasis on Yield in Tomato Imposed by a Domestication Gene. Cell 2017, 169, 1142-1155.e12. [CrossRef] 
57. Jacob, P.; Avni, A.; Bendahmane, A. Translational Research: Exploring and Creating Genetic Diversity. Trends Plant Sci. 2018, 23, 42-52. [CrossRef]

58. Cong, L.; Ran, F.A.; Cox, D.; Lin, S.; Barretto, R.; Habib, N.; Hsu, P.D.; Wu, X.; Jiang, W.; Marraffini, L.A.; et al. Multiplex Genome Engineering Using CRISPR/Cas Systems. Science 2013, 339, 819-823. [CrossRef]

59. Shan, Q.; Wang, Y.; Chen, K.; Liang, Z.; Li, J.; Zhang, Y.; Zhang, K.; Liu, J.; Voytas, D.F.; Zheng, X.; et al. Rapid and Efficient Gene Modification in Rice and Brachypodium Using TALENs. Mol. Plant 2013, 6, 1365-1368. [CrossRef]

60. Nelson, D.R.; Schuler, M.A.; Paquette, S.M.; Werck-Reichhart, D.; Bak, S. Comparative Genomics of Rice and Arabidopsis. Analysis of 727 Cytochrome P450 Genes and Pseudogenes from a Monocot and a Dicot1[w]. Plant Physiol. 2004, 135, 756-772. [CrossRef]

61. Zhou, H.; Liu, B.; Weeks, D.P.; Spalding, M.H.; Yang, B. Large chromosomal deletions and heritable small genetic changes induced by CRISPR/Cas9 in rice. Nucleic Acids Res. 2014, 42, 10903-10914. [CrossRef]

62. Han, Y.; Luo, D.; Usman, B.; Nawaz, G.; Zhao, N.; Liu, F.; Li, R. Development of High Yielding Glutinous Cytoplasmic Male Sterile Rice (Oryza sativa L.) Lines through CRISPR/Cas9 Based Mutagenesis of Wx and TGW6 and Proteomic Analysis of Anther. Agronomy 2018, 8, 290. [CrossRef]

63. Usman, B.; Nawaz, G.; Zhao, N.; Liu, Y.-G.; Li, R. Generation of High Yielding and Fragrant Rice (Oryza sativa L.) Lines by CRISPR/Cas9 Targeted Mutagenesis of Three Homoeologs of Cytochrome P450 Gene Family and $O s B A D H 2$ and Transcriptome and Proteome Profiling of Revealed Changes Triggered by Mutations. Plants 2020, 9, 788. [CrossRef]

64. Zhang, H.; Zhang, J.; Wei, P.; Zhang, B.; Gou, F.; Feng, Z.; Mao, Y.; Yang, L.; Zhang, H.; Xu, N.; et al. The CRISPR/Cas9 system produces specific and homozygous targeted gene editing in rice in one generation. Plant Biotechnol. J. 2014, 12, 797-807. [CrossRef]

65. Yamaguchi, S. Gibberellin Metabolism and its Regulation. Annu. Rev. Plant Biol. 2008, 59, 225-251. [CrossRef]

66. Hedden, P.; Thomas, S.G. Gibberellin biosynthesis and its regulation. Biochem. J. 2012, 444, 11-25. [CrossRef]

67. Fukazawa, J.; Mori, M.; Watanabe, S.; Miyamoto, C.; Ito, T.; Takahashi, Y. DELLA-GAF1 Complex Is a Main Component in Gibberellin Feedback Regulation of GA20 Oxidase 2. Plant Physiol. 2017, 175, 1395-1406. [CrossRef]

68. Boden, S.A.; Weiss, D.; Ross, J.J.; Davies, N.W.; Trevaskis, B.; Chandler, P.M.; Swain, S.M.; Krajinski, F.; Courty, P.-E.; Sieh, D.; et al. EARLY FLOWERING 3 Regulates Flowering in Spring Barley by Mediating Gibberellin Production and FLOWERING LOCUS T Expression. Plant Cell 2014, 26, 1557-1569. [CrossRef]

69. Fukazawa, J.; Nakata, M.; Ito, T.; Matsushita, A.; Yamaguchi, S.; Takahashi, Y. bZIP transcription factor RSG controls the feedback regulation ofNtGA20ox1via intracellular localization and epigenetic mechanism. Plant Signal. Behav. 2011, 6, 26-28. [CrossRef]

70. Yang, G.; Inoue, A.; Takasaki, H.; Kaku, H.; Akao, S.; Komatsu, S. A Proteomic Approach to Analyze Auxinand Zinc-Responsive Protein in Rice. J. Proteome Res. 2005, 4, 456-463. [CrossRef]

71. Komatsu, S.; Zang, X.; Tanaka, N. Comparison of Two Proteomics Techniques Used to Identify Proteins Regulated by Gibberellin in Rice. J. Proteome Res. 2006, 5, 270-276. [CrossRef]

72. Shen, S.; Sharma, A.; Komatsu, S. Characterization of proteins responsive to gibberellin in the leaf-sheath of rice (Oryza sativa L.) seedling using proteome analysis. Biol. Pharm. Bull. 2003, 26, 129-136. [CrossRef]

73. Tanaka, N.; Konishi, H.; Khan, M.M.K.; Komatsu, S. Proteome analysis of rice tissues by two-dimensional electrophoresis: An approach to the investigation of gibberellin regulated proteins. Mol. Genet. Genom. 2003, 270, 485-496. [CrossRef]

74. Hedden, P. The genes of the Green Revolution. Trends Genet. 2003, 19, 5-9. [CrossRef]

75. Li, J.; Jiang, J.; Qian, Q.; Xu, Y.; Zhang, C.; Xiao, J.; Du, C.; Luo, W.; Zou, G.; Chen, M.; et al. Mutation of Rice BC12/GDD1, Which Encodes a Kinesin-Like Protein That Binds to a GA Biosynthesis Gene Promoter, Leads to Dwarfism with Impaired Cell Elongation. Plant Cell 2011, 23, 628-640. [CrossRef]

76. Kuijt, S.; Greco, R.; Agalou, A.; Shao, J.; Hoen, C.C.J.; Overnäs, E.; Osnato, M.; Curiale, S.; Meynard, D.; van Gulik, R.; et al. Interaction between the GROWTH-REGULATING FACTOR and KNOTTED1-LIKE HOMEOBOX Families of Transcription Factors1[W]. Plant Physiol. 2014, 164, 1952-1966. [CrossRef]

77. Omidbakhshfard, M.A.; Proost, S.; Fujikura, U.; Mueller-Roeber, B. Growth-Regulating Factors (GRFs): A Small Transcription Factor Family with Important Functions in Plant Biology. Mol. Plant 2015, 8, 998-1010. [CrossRef] 
78. van der Knaap, E.; Kim, J.H.; Kende, H. A novel gibberellin-induced gene from rice and its potential regulatory role in stem growth. Plant Physiol. 2000, 122, 695-704. [CrossRef]

79. Kim, J.H.; Choi, D.; Kende, H. The AtGRF family of putative transcription factors is involved in leaf and cotyledon growth in Arabidopsis. Plant J. 2003, 36, 94-104. [CrossRef]

80. Bao, M.; Bian, H.; Zha, Y.; Li, F.; Sun, Y.; Bai, B.; Chen, Z.; Wang, J.; Zhu, M.; Han, N. miR396a-Mediated Basic Helix-Loop-Helix Transcription Factor bHLH74 Repression Acts as a Regulator for Root Growth in Arabidopsis Seedlings. Plant Cell Physiol. 2014, 55, 1343-1353. [CrossRef]

81. Choi, D.; Kim, J.H.; Kende, H. Whole genome analysis of the OsGRF gene family encoding plant-specific putative transcription activators in rice (Oryza sativa L.). Plant Cell Physiol. 2004, 45, 897-904. [CrossRef] [PubMed]

82. Liu, H.; Guo, S.; Xu, Y.; Li, C.; Zhang, Z.; Zhang, D.; Xu, S.; Zhang, C.; Chong, K. OsmiR396d-regulated OsGRFs function in floral organogenesis in rice through binding to their targets OsJMJ706 and OsCR4. Plant Physiol. 2014, 165, 160-174. [CrossRef]

83. Day, B.; Tanabe, S.; Koshioka, M.; Mitsui, T.; Itoh, H.; Ueguchi-Tanaka, M.; Matsuoka, M.; Kaku, H.; Shibuya, N.; Minami, E. Two Rice GRAS Family Genes Responsive to N-Acetylchitooligosaccharide Elicitor are Induced by Phytoactive Gibberellins: Evidence for Cross-Talk between Elicitor and Gibberellin Signaling in Rice Cells. Plant Mol. Biol. 2004, 54, 261-272. [CrossRef] [PubMed]

84. Prisic, S.; Xu, M.; Wilderman, P.R.; Peters, R.J. Rice Contains Two Disparate ent-Copalyl Diphosphate Synthases with Distinct Metabolic Functions1. Plant Physiol. 2004, 136, 4228-4236. [CrossRef]

85. Salvucci, M.E.; Ogren, W.L. The mechanism of Rubisco activase: Insights from studies of the properties and structure of the enzyme. Photosynth. Res. 1996, 47, 1-11. [CrossRef] [PubMed]

86. Chen, F.; Tholl, D.; Bohlmann, J.; Pichersky, E. The family of terpene synthases in plants: A mid-size family of genes for specialized metabolism that is highly diversified throughout the kingdom. Plant J. 2011, 66, 212-229. [CrossRef] [PubMed]

87. Hanai, H.; Nakayama, D.; Yang, H.; Matsubayashi, Y.; Hirota, Y.; Sakagami, Y. Existence of a plant tyrosylprotein sulfotransferase: Novel plant enzyme catalyzing tyrosine O-sulfation of preprophytosulfokine variants in vitro. FEBS Lett. 2000, 470, 97-101. [CrossRef]

88. Komori, R.; Amano, Y.; Ogawa-Ohnishi, M.; Matsubayashi, Y. Identification of tyrosylprotein sulfotransferase in Arabidopsis. Proc. Natl. Acad. Sci. USA 2009, 106, 15067-15072. [CrossRef]

89. Jin, Y.; Zhang, C.; Liu, W.; Tang, Y.; Qi, H.; Chen, H.; Cao, S. The Alcohol Dehydrogenase Gene Family in Melon (Cucumis melo L.): Bioinformatic Analysis and Expression Patterns. Front. Plant Sci. 2016, 7, 670. [CrossRef]

90. Hattori, Y.; Nagai, K.; Furukawa, S.; Song, X.-J.; Kawano, R.; Sakakibara, H.; Wu, J.; Matsumoto, T.; Yoshimura, A.; Kitano, H.; et al. The ethylene response factors SNORKEL1 and SNORKEL2 allow rice to adapt to deep water. Nature 2009, 460, 1026-1030. [CrossRef]

91. Takasaki, H.; Mahmood, T.; Matsuoka, M.; Matsumoto, H.; Komatsu, S. Identification and characterization of a gibberellin-regulated protein, which is ASR5, in the basal region of rice leaf sheaths. Mol. Genet. Genom. 2008, 279, 359-370. [CrossRef] [PubMed]

92. Kim, H.; Lee, K.; Hwang, H.; Bhatnagar, N.; Kim, D.-Y.; Yoon, I.S.; Byun, M.-O.; Kim, S.T.; Jung, K.-H.; Kim, B.-G. Overexpression of PYL5 in rice enhances drought tolerance, inhibits growth, and modulates gene expression. J. Exp. Bot. 2014, 65, 453-464. [CrossRef] [PubMed]

93. Welti, R. Plant lipidomics: Discerning biological function by profiling plant complex lipids using mass spectrometry. Front. Biosci. J. Virtual Libr. 2007, 12, 2494-2506. [CrossRef] [PubMed]

94. Rojas, C.M.; Senthil-Kumar, M.; Tzin, V.; Mysore, K.S. Regulation of primary plant metabolism during plant-pathogen interactions and its contribution to plant defense. Front. Plant Sci. 2014, 5. [CrossRef] [PubMed]

95. Ma, X.; Zhang, Q.; Zhu, Q.; Liu, W.; Chen, Y.; Qiu, R.; Wang, B.; Yang, Z.; Li, H.; Lin, Y.; et al. A Robust CRISPR/Cas9 System for Convenient, High-Efficiency Multiplex Genome Editing in Monocot and Dicot Plants. Mol. Plant 2015, 8, 1274-1284. [CrossRef]

96. Xie, X.; Ma, X.; Zhu, Q.; Zeng, D.; Li, G.; Liu, Y.-G. CRISPR-GE: A Convenient Software Toolkit for CRISPR-Based Genome Editing. Mol. Plant 2017, 10, 1246-1249. [CrossRef]

97. Ma, X.; Liu, Y. CRISPR/Cas9-Based Multiplex Genome Editing in Monocot and Dicot Plants. Curr. Protoc. Mol. Biol. 2016, 115, 31.6.1-31.6.21. [CrossRef] [PubMed] 
98. Hiei, Y.; Ohta, S.; Komari, T.; Kumashiro, T. Efficient transformation of rice (Oryza sativa L.) mediated by Agrobacterium and sequence analysis of the boundaries of the T-DNA. Plant J. 1994, 6, 271-282. [CrossRef] [PubMed]

99. Xu, X.; Kawasaki, S.; Fujimura, T.; Wang, C. A protocol for high-throughput extraction of DNA from rice leaves. Plant Mol. Biol. Rep. 2005, 23, 291-295. [CrossRef]

100. Ma, X.; Chen, L.; Zhu, Q.; Chen, Y.; Liu, Y.-G. Rapid Decoding of Sequence-Specific Nuclease-Induced Heterozygous and Biallelic Mutations by Direct Sequencing of PCR Products. Mol. Plant 2015, 8, 1285-1287. [CrossRef]

101. Suge, H. Ethylene and Gibberellin: Regulation of Internodal Elongation and Nodal Root Development in Floating Rice. Plant Cell Physiol. 1985, 26, 607-614. [CrossRef]

102. Peng, P.; Liu, L.; Fang, J.; Zhao, J.; Yuan, S.; Li, X. The rice TRIANGULAR HULL1 protein acts as a transcriptional repressor in regulating lateral development of spikelet. Sci. Rep. 2017, 7, 13712. [CrossRef]

103. Chen, L.; Huang, Y.; Xu, M.; Cheng, Z.; Zhang, D.; Zheng, J. iTRAQ-Based Quantitative Proteomics Analysis of Black Rice Grain Development Reveals Metabolic Pathways Associated with Anthocyanin Biosynthesis. PLoS ONE 2016, 11, e0159238. [CrossRef]

104. Pfaffl, M.W. A new mathematical model for relative quantification in real-time RT-PCR. Nucleic Acids Res. 2001, 29, e45. [CrossRef]

(C) 2020 by the authors. Licensee MDPI, Basel, Switzerland. This article is an open access article distributed under the terms and conditions of the Creative Commons Attribution (CC BY) license (http://creativecommons.org/licenses/by/4.0/). 